\title{
MARCA, ARTE DE LA MERCADERÍA Y PROTORGANIZACIÓN DE LA ESTRUCTURA RECAUDATORIA EN LA VALENCIA DEL TRESCIENTOS
}

\author{
MARKS, BOOKS OF MERCHANTS AND THE STRUCTURE \\ OF FISCAL COLLECTION IN THE XIV CENTURY CITY OF VALENCIA
}

\author{
ANDRÉS DÍAZ BORRÁS \\ IES Camp de Morvedre (Sagunt)
}

\begin{abstract}
Resumen: Existe una relación entre marcas, libros de mercaderes y organización hacendística. Nuestro propósito es exponer como los tres aspectos han incidido en la evolución económica de Valencia y en su desarrollo fiscal. La razón de la fijación de represalias comerciales o marcas fue la actividad corsaria. Por otro lado, los libros de mercaderes son el instrumento precioso para conocer la estructura de las compañías comerciales. Ambos factores están en el origen del proceso impositivo de época medieval.
\end{abstract}

Palabras clave: historia marítima; fiscalidad; historia de los negocios.

\begin{abstract}
There is an analogy between marks, books of merchants and fiscal organization. Our purpose is to explain how the three aspects have impacted in the economic evolution of Valencia and in its financial development. Corsairs' activity was the reason for marks or commercial reprisals fixation. On the other hand, the books of merchants are a precious instrument to know the structure of medieval commercial companies. Both factors are in the origin of the tax process in Middle Ages.
\end{abstract}

Keywords: maritime history; taxation; business history.

\section{SUMARIO}

1. La represalia como argumento jurídico medieval.- 2. Los Llibres de l'Art de la Mercaderia como aplicación jurídica.- 3. Piratería y represalia: el asalto a la coca Sant Nicolau.- 4. El libro de la mercadería de Valldaura.- 5. La marca contra franceses y la inclusión de los mercaderes afectados en la red de reintegración de dinero robado.

El hermanastro del rey Pedro el Ceremonioso, Fernando, Señor de Tortosa y Albarracín, hijo de Alfonso el Benigno, había dado un documento, el 24 de diciembre de 1358, en calidad de Gobernador General del Reino de Valencia, por el cual se designaba a micer Mateu de Montull como magistrado competente en el pleito que se iba a dilucidar entre los hijos y viuda de Bernat de Valldaura, por un lado, y Domingo Aznar, tutor de aquellos, por otro ${ }^{1}$. Los demandantes acusaban al curador Aznar por su mala

${ }^{1}$ Archivo Municipal de Valencia (AMV), Llibres judiciaris de la Cort del Racional $i$ Jurats de València, pp-4. mà 1, f. 1r-v. En concreto de la Apel-lació de Na Valldaura contra En Domingo Aznar. El documento por el que Montull era designado juez del caso fue hecho público en Valencia el 10 de enero de 1359, cuando el procurador de los hijos de Valldaura, por intercesión del notario público de 
gestión, que había hecho disminuir considerablemente el patrimonio de los Valldaura. Así pues, era acusado de propósito torticero y mala intención en la gestión de aquellos recursos y de abusos en los salarios que había cobrado, en virtud del desempeño de su función de valedor de los huérfanos y viuda ${ }^{2}$. En cualquier caso, resulta, para nosotros, muy difícil de establecer la intencionalidad de Domingo Aznar en el amparamiento de los Valldaura. De hecho, también lo fue para Mateu de Montull que, al final del proceso, fue incapaz de establecer responsabilidades concretas y nítidas, que constituyesen delito y no una gestión desafortunada y torpe de los intereses, por los que debía velar. Tampoco pudo discernir si por el contrario había mala voluntad por parte de quienes se consideraban perjudicados y en realidad disponían de menos recursos y solvencia económica de la que ellos pensaban, atribuyendo, falsamente, a Aznar acciones que jamás había cometido ${ }^{3}$.

A quienes estén acostumbrados a tratar con documentos judiciales medievales no les debe extrañar esta conclusión. Los comienzos, prometedores de muchos de estos procesos, son simplemente la antesala de una decepción, a veces incompren-

la Corte Bartomeu Vilalba, hará leer la carta oficial. El día 11 fueron convocados los implicados por el juez. El propósito de esa reunión será fijar una fecha a partir de la cual preparar el comienzo del juicio y, probablemente más importante, fijar la cuantía y los plazos de cobro del salario del juez. A esta reunión asistieron Domingo Aznar y su procurador Bernat Feliu, por un lado, y Pere d'Òdena, procurador de los hijos de Valldaura por otro. AMV, Llibres judiciaris, mà 1, ff. 2r-3r. Lo cierto es que el pleito quedó inmediatamente paralizado, primero por la incomparecencia sucesiva de cada una de las partes y segundo, probablemente, porque no se llegaría a un acuerdo para satisfacer los legítimos deseos del juez de cobrar su salario. Así se sucedieron las incomparecencias del 19, 26, 28 de enero, del 1 y del 4 de febrero: AMV, Ibidem, ff. 3r-6r. Sin duda, ante este cúmulo de incomparecencias Montull estaría a punto de desistir de su propósito, a no ser por la intervención, de nuevo, del Infante Fernando, quien por mediación de Pere d'Òdena, ratificaba a micer Mateu como juez competente en la causa. Por fin, en octubre de 1359, unos ocho meses después de anunciado, el juicio dará comienzo.

${ }^{2}$ El martes 15 de octubre, ante micer Mateu de Montull, comparecieron En Martí de Torres, escribano, y los implicados en el pleito Pere d'Òdena, por un lado y Domingo Aznar con su procurador En Bernat Feliu. D'Òdena presentará un escrito con nueve puntos en el que explicaba las causas por las cuales había interpuesto la demanda. En primer lugar consideraba que Aznar debía ser removido de la tutoría de los Valldaura, en tanto en cuanto la causa no se definiese. Decía, en segundo lugar, que alguien tendría que dar cuenta de los cinco mil sueldos de la dote de la hija del difunto, que fueron entregados por Guillem Magencoses y Bernat Cirart al tutor y que se habían volatilizado. En tercer lugar, acusaba a Aznar de querer hacer todo el daño posible a los Valldaura, y por eso se fijó un salario para su tutoría desorbitado, de noventa libras (mil ochocientos sueldos), que compartiría con Sanxo Martí, frente a los cien sueldos anuales que fijara el difunto Valldaura. Por este motivo, los ingresos de censales, que corresponderían a sus tutelados habían disminuido considerablemente absorbidos por las ansias del curador. AMV, Judiciari, mà $1^{\mathrm{a}}$, f. 21r y mà 2a , f. 21 v.

${ }^{3}$ En presencia de Domingo Aznar, tutor suspendido de su cargo, por el Justicia Civil de Valencia, en la administración de la herencia de los huérfanos de Bernat de Valldaura, comparece Jaume Boschà, representante de Domingo Johan, notario procurador de los huérfanos, desde la suspensión de Aznar, y dice, ante Pere Fuster, doctor en leyes, designado por el rey para entender en la apelación, y reclama cualquier cantidad que pueda corresponder a los herederos del difunto, doc., fechado a 19 de octubre de 1359. AMV, Judiciari, mà $2^{\mathrm{a}}$, ff. 40r-41r. Por otro lado, el miércoles 23 de octubre de 1359, los jueces delegados en el caso de la apelación y de la resolución del pleito establecen que el último día de octubre habrá reunión de la Corte para fallar el litigio. AMV, Judiciari, mà 2a ,ff. 41v-42v. El martes, 29 de octubre se exponen los alegatos definitivos: Aznar expone la falsedad de los documentos argüidos por d'Òdena, mientras que éste requiere el interrogatorio del anterior para encontrar la verdad. AMV, Judiciari, mà 2a , ff. 42v-44v. El día 5 de noviembre, Mateu de Montull, auxiliado por En Martí de Torres, establecen que el fallo sería el día de San Martín, día 11 de noviembre. AMV, Judiciari, mà $2^{a}$, ff. 44v-45r. Por fin el día sábado, 9 de noviembre, se aplazaba el fallo definitivamente para el día 30 de noviembre de 1359, festividad de San Andrés. AMV, Judiciari, mà 2a , f. 45r. El manuscrito acaba en este punto, no quedando constancia de la promulgación de alguna sentencia. 
sible, por su final difuso, que no se resuelve con un fallo judicial previsible sino en el limbo de una próxima reunión, que ya jamás llegará a realizarse. Muchas veces, parece que las partes hubiesen acordado, sin dejar constancia escrita, una resolución del conflicto al margen de la vía judicial. Es como si ésta fuera un último recurso, pero al que no se apela sino se han agotado otras vías: el pacto o la componenda extrajudicial, por ejemplo. Dado que en muchos casos, esos arreglos son posibles, los pleitos quedan interrumpidos, sin que seamos capaces de explicar racionalmente lo que ha pasado. Por otro lado, hay un gran desconocimiento de los mecanismos judiciales medievales, distintos de los actuales, en los que tampoco nos movemos con absoluta soltura, y en los que la constancia escrita no siempre quedaba reflejada y archivada para la posterioridad. Toda esta procelosa realidad conspira, casi siempre, para hacer ininteligible la vida procesal medieval, llevándonos a nosotros al infortunio y la desesperanza de no ser capaces de interpretar correctamente el pasado ${ }^{4}$

No obstante, en este caso, es cierto que las sorpresas que contenía el desarrollo del proceso compensaban las dificultades de seguir su lectura. En efecto, dos aspectos resaltan, sobre el resto, en la médula del pleito. Por un lado, las referencias a la marca, que en un momento determinado fue fijada contra súbditos del rey de Francia. No suele ocurrir que dispongamos de fehaciente información relacionada con el cobro y satisfacción a súbditos de la Corona de Aragón, por actos ilegales, cometidos por franceses. Normalmente, las informaciones de que disponemos siempre se refieren a las circunstancias contrarias. Por otro lado, la referencia al libro del arte de la mercadería de Valldaura, del que se dan, aparentemente, transcripciones concretas, es también un hito singular. Es singular debido a que no contamos con muchos indicios de esta categoría, tan detallados y precisos, para una época tan temprana. Ambos elementos, desde nuestro punto de vista, representan peculiaridades y aportaciones interesantes, que contribuyen a esclarecer, un poco más, el ámbito de los negocios en el poco iluminado mundo de la primera mitad del siglo XIV. La profundización en su estudio y conocimiento aportará luz y más información sobre un ámbito que todavía está muy lejos de haber sido explicado. Por otro lado, las faltas a las que hacemos referencia nos pueden llevar a considerar conveniente la profundización en el análisis de las repercusiones internas, que pudo tener el establecimiento de marcas para la vida económica valenciana. La organización del cobro y explotación de la marca, aunque en Valencia quedara lejana no sería desconocida. No faltaría gente capaz de entender los procedimientos, mecanismos y funciones que activaban los cobros, su regularidad o su cuantía. Todas estas consideraciones servirán, sin ningún género de duda, para la mejora organizativa de la economía privada, pero también serviría para dotar a las instituciones de instrumentos adecuados y aplicables en situaciones distintas o problemas diversos: fijación de impuestos locales, cobros de imposiciones del General, etc.

\section{LA REPRESALIA COMO ARGUMENTO JURÍDICO MEDIEVAL}

Parece un argumento jurídico poco reprochable el pensar que un inocente no debe pagar las culpas de otros sujetos de derecho. Si no fuera así, no habría ninguna garantía de que la ley nos protege, antes al contrario, parecería sensato desconfiar de un mundo en el que, en cualquier momento, pudieras verte legalmente acusado con

\footnotetext{
${ }^{4}$ Es ejemplificador el caso de Úrsola, esposa de un acaudalado labrador de Morvedre, que por intercesión de su amante intentó asesinar a su esposo, suministrándole venenos. El resultado final de este proceso es paradigmático de cuanto decimos y esclarecedor. Andrés DíAZ BorRÁs, Contra Úrsola. Morvedre, 1425-1428. Una aproximación histórica, Sagunto, 2007.
} 
fundamentos sólidos, por un delito no cometido objetivamente. No obstante, este tipo de pensamiento, aparentemente bien trabado, tropieza con una incontestable contradicción, que llevada hasta sus extremos puede ponernos frente a una auténtica injusticia. El problema se puede esbozar en los siguientes términos: aquel perjudicado por otro, que no es repuesto en su estado, es doblemente vejado, porque al padecimiento que supone el delito hay que añadir el que significa la imposibilidad de una legítima reparación.

Así las cosas, los juristas medievales se encontraron, como tantas veces, con un dilema sin solución aparente: o los inocentes siniestrados eran doblemente perjudicados o se extendía la consideración de delito a una serie de inocentes, de manera impropia, para satisfacer a la víctima. Esta disyuntiva era más fácilmente resoluble cuando todos los implicados eran súbditos de un mismo señor. En estos casos el problema podía ser acotado por el freno superior que los gobernaba. Con todo y con eso, las represalias y los pleitos no dejaron de aparecer entre miembros de una misma soberanía, muchas veces vinculados a fenómenos sociales como las bandositats $^{5}$. No obstante, cuando esto ocurría, podían arbitrarse, desde la autoridad, medidas compensatorias, acuerdos entre las partes y también en algunos casos venganzas extrajudiciales toleradas.

Sin embargo, las cosas cambiaban mucho cuando siniestrados y delincuentes pertenecían a señorías diversas. Aquí se ponía en cuestión, además de la injusticia flagrante, las relaciones entre las señorías y la eficacia de sus aparatos administrativos para resolver el conflicto. Era pues un tema de desarrollo jurídico pero también de diplomacia internacional y de coyuntura política; que se mezclaban y mediatizaban todo el asunto. Por lo que se refiere a los conflictos comerciales, la normativa de tradición romanista, imperturbable ante la letra escrita, probablemente hubiera sido partidaria de evitar el pago de un delito a elementos no culpables ${ }^{6}$.

\footnotetext{
5 "Las expresiones de solidaridad vecinal se articulan con el marco jurídico legal: en 1336 el rechazo, por la corte judicial de Gerona, de la reclamación presentada contra un gerundense por parte de un mercader de Tortosa, comporta la protección de esta ciudad a su conciudadano y a una reclamación que, al no ser atendida, se considera "fadiga de dret", dando lugar a un proceso de marca contra los bienes de cualquier gerundense, que será respondido desde Gerona. La noción de solidaridad colectiva se imbrica así con el ejercicio judicial ordinario: agotadas las primeras actuaciones ordinarias sin obtener satisfacción de la reclamación, el mismo procedimiento jurídico permite actuar contra el colectivo al que pertenece el inculpado mediante la marca o incautación de bienes. La noción de solidaridad colectiva se imbrica así con el ejercicio judicial ordinario: agotadas las primeras actuaciones ordinarias sin obtener satisfacción de la reclamación, el mismo procedimiento jurídico permite actuar contra el colectivo al que pertenece el inculpado mediante la marca o incautación de bienes. La insuficiencia de esta vía, o su incapacidad para detener a inculpados en crímenes, justifica la actuación conjunta y armada contra el colectivo que protege en su seno al inculpado. Esta respuesta también debe de activarse de modo regulado, justificada por el procedimiento judicial que ha recorrido las fases previas de la reclamación y conducida por quien goza de la representación soberana, combinándose así con la cohesión solidaria del colectivo local ya reivindicada y reconocida en los primeros reconocimientos de organización municipal” (Flocel SABATÉ, El somatén en la Cataluña Medieval, “Clío \& Crimen”, 3 (2006), pp. 209-304, en concreto p. 214. También, p. 222: "Dado que el somatén, más que una respuesta espontánea, es la conclusión de un determinado procedimiento jurídico, el recorrido formal hasta su aplicación será conocido como proceso de sometent: "procés de sometent", "processum soni emissi". Efectuadas las oportunas reclamaciones de justicia por el correspondiente ordinario, la denegación -"fadiga de dret"- justifica resarcirse con un proceso de "marca" que permite requisar los bienes de cualquier miembro de la jurisdicción del inculpado o, si es el caso, exigir con las armas la cesión del inculpado o el resarcimiento de la injuria mediante el proceso de somatén. Formalmente corresponde al oficial ordinario valorar estos extremos. En la práctica, siempre actúa tras el correspondiente posicionamiento municipal".

6 "El dret de marca o de represàlia es basava en una llunyana tradició d'origen germànic en la qual l'error comès per un membre podia, segons les circumstàncies, afectar tota la col-lectivitat. Aquesta
} 
Sin embargo, los jueces europeos, también los del Mediterráneo occidental, más romanizados, no atendieron a esta reflexión y se decantaron por una versión aparentemente más bárbara, más germánica en la apariencia, el castigo colectivo como símbolo de la solidaridad del conjunto urbano dominante de las tropelías cometidas por los miembros de su grupo ${ }^{7}$. Al fin y al cabo, de no ser así, la proliferación del latrocinio marítimo y la piratería hubiera colapsado todas las negociaciones pacíficas ${ }^{8}$. En realidad, es posible que no se trate tanto de una disyuntiva entre tradiciones jurídicas occidentales como de un uso mucho más arraigado en la memoria de la gente de la mar, independientemente de su origen. De hecho marcas y represalias también existieron en las relaciones entre la Corona de Aragón y el mundo musulmán, por ejemplo ${ }^{9}$. En realidad, es probable que el castigo colectivo pretendiera conseguir, de las rudimentarias administraciones medievales, una mejora en su eficacia a la hora de perseguir el delito y prevenirlo, disuadiendo de su impunidad. Así pues conviene puntualizar que la legislación sobre represalias, más que un vestigio de la oscura barbarie poco romanizada, fue un evidente progreso en el pensamiento jurídico medieval fruto de una experiencia plural y tal vez multicultural.

Las represalias comerciales, conocidas también en todas partes como marcas, buscaron servir, en primer lugar, para resarcir a los afectados pero también para mejorar los canales internacionales de aplicación de la justicia. Su propósito era el de evitar que se produjeran frustrantes lances legales. En efecto, su carácter disuasorio estaría concebido con el propósito de que las autoridades soberanas intervinieran, rápida y eficazmente, para impedir que el delito de un connatural quedara sin castigo y la parte contraria viera satisfechos sus legítimos derechos, en la colectividad nativa

pràctica jurídica, radicalment contrària al dret romà, que s'oposa totalment que es pugui pagar una culpa de la qual s'és innocent, es va començar a partir del segle XII com a única alternativa d'obtenir justícia quan, per motiu de diferent jurisdicció, aquesta es feia impossible. Com molt bé diu R. DE MAs LATRIE, Du droit de marque au droit de représailles au Moyen Âge. Bibliothèque de l'École de Chartes, VIè série, II. Paris, 1885, no és d'estranyar que aquestes marques apareguessin generalment relacionades amb el mon del comerç i dels negocis mercantils" (Lluís DUCH ÁLVAREZ, Armes espirituals $i$ materials: política. Antropologia de la vida quotidiana, 4,2. Abadia de Montserrat, 2001, p. 185).

7 "Un altre estudi pioner fou el que dedicà a les represàlies i al dret de marca a l'edat mitjana, que obeïa, deia, al "desig d'obtenir la restauració del dret vulnerat, l'aspiració de reprendre els béns perduts o l'equivalència del que fou robat o destruït" i, naturalment, al desig de venjança; el principi de la solidaritat entre l'agressor i els convilatans o connacionals permetia exercir aquest dret de restauració dels béns perduts contra un cercle ampli de persones" (Maria Teresa FERRER MALLOL, Joaquim Miret i Sans: Semblança biogràfica, Barcelona, 2003. 54 p. [Conferència pronunciada davant el Ple de 1'Institut d'Estudis Catalans, per M. Teresa Ferrer i Mallol el dia 17 de juny de 2002]).

${ }^{8}$ En palabras del profesor Gilissen "Même lorsque le village devient ville, la solidarité peut subsister, sur tout lorsque la ville se développe au départ d'une communauté de marchands. Dans l'Europe du bas moyen âge par exemple, existait le droit de marque ou de représailles, en vertu duquel un bourgeois d'une ville de trouvant dans une ville étrangère, pouvait y être contraint de payer la dette d'un autre bourgeois de sa ville" (John GILISSEN, Les sûretés personnelles. Première Partie. Synthèse Générale Civilisations Archaïques, Antiques, Islamiques et Orientales, Bruxelles, 1974, p. 45).

9 "Durante el siglo XIV las relaciones comerciales de la Corona de Aragón con el Levante mediterráneo no siempre fueron fáciles. Los catalanes disponían de un consulado en Beirut, desde 1347, trasladado en 1379 a Damasco. Pero en 1365 se dejan arrastrar a una cruzada del rey de Chipre, Pedro I, contra Egipto. Alejandría fue saqueada, y el sultán ordenó represalias contra los mercaderes catalanes. Sólo cinco años después, en 1370, fue firmada la paz, reabriéndose al comercio cristiano el puerto de Alejandría. Nuevos incidentes en 1386, con la captura de cargamentos egipcios embarcados en naves tunecinas, obligaron a una suspensión temporal de relaciones" (Pau CATEURA BENNÀSSER, Mundos mediterráneos: el reino de Mallorca y el sultanato mameluco (siglos XIII-XV), "Espacio, Tiempo y Forma, Serie III, Historia Medieval", 13 (2000), pp. 85-101. En concreto p. 90). 
del delincuente ${ }^{10}$. Al fin y al cabo, se podría pensar que la señoría, que tan torpemente hubiera actuado, primero al dar origen a un infractor de la ley y después al permitir que se saliera con la suya, sin ninguna pena, merecería alguna clase de corrección o llamada al orden ${ }^{11}$. Así pues, las marcas constituían una forma de racionalizar el castigo o la satisfacción judicial, que de otra manera podría acabar siendo mucho más violenta, imprevisible y destructiva.

Por otro lado, esta forma de represión era susceptible de aplicación en épocas y circunstancias diversas, de acuerdo con la voluntad y la conveniencia de los afectados. Una norma tan tornadiza se ve, por ejemplo, en el Señorío de Vizcaya a lo largo de toda la Edad Media. En efecto, debido a las peculiaridades de estos territorios y de las villas marineras de Vizcaya y Guipúzcoa, resultaba muchas veces inconveniente mantener marcas contra otros súbditos de señorías que hubiesen actuado de manera incorrecta, puesto que estos mismos aprovisionaban el litoral cantábrico con bienes y vituallas imprescindibles. Eso generará que las autoridades vascongadas constantemente intenten superar la situación de marcas contra súbditos o integrantes de otras señorías, siempre con el propósito de mantener aprovisionados sus puertos ${ }^{12}$.

10 "As represalias concebiam-se apenas como instrumento utilizavel quando se nao pudesse confiar nos meios jurisdicionais e como forma de efectivar a obligaçao existente na vida internacional de prestar jusriça aos estrangeiros sem delongas e malícias" (Ruy Manuel de ALBUQUERQUE, As represalias. Estudo de História do Direito portugués (sécs. XV e XVI), Tomo I, Lisboa, 1972, p. 826).

${ }^{11}$ Así se puede pensar que lo han entendido algunos de los historiadores anglosajones que más se han preocupado por este tipo de cuestiones: Maurice Hugh KEEN, The law of war in the late middle ages, London-Toronto, 1965. Hay multitud de reediciones de este libro. Emily Sohmer TAI, Honor among thieves: piracy, restitution, and reprisal in Genoa, Venice, and the Crown of Catalonia-Aragon, 1339-1417. Tesis de doctorado inédita leída en Harvard University, 1996. También puede ser muy interesante su trabajo titulado Marking water: piracy and property in the Pre-Modern West en el Congreso Seascapes, littoral cultures, and trans-oceanic exchanges (Washington D. C.12-15 febrero 2003). Edición digital de Debbie Ann Doyle y Brandon Schneider y formateada por Chris Hale, para www.historycooperative.org/proceedings [consulta: 15.05.2008]. Por último también es muy interesante la obra de Keechang KIM, Aliens in Medieval Law. The origins of modern citizenship, Cambridge, 2001. En especial nos ha interesado el apartado que hacía referencia al trato a los extranjeros en situación de paz y guerra, p. 98.

12 "En ocasiones, la ejecución de las represalias tenía un efecto colateral pernicioso: afectaba la actividad comercial marítima hasta el punto de que los mercaderes y los transportistas rehusaban conducir sus naves por aquellos lugares donde temieran ser asaltados. En el caso de las provincias costeras vascas este efecto colateral repercutía de forma especial, ya que su economía y el abastecimiento de vituallas para su mantenimiento descansaba en buena medida en el comercio marítimo" (Iñaki BAZÁN, 'Degollaron a todos los dichos treynta y tres ingleses y asy degollados dis que los lançaron en la mar'. Las hermandades vascas y la lucha contra la piratería en la Baja Edad Media, "Itsas Memoria. Revista de Estudios Marítimos del País Vasco", 5 (2006), pp. 69-93. En concreto p. 77). En la década de los 90 se instituyó la Hermandad de Bizkaya, cuyas ordenanzas en cuanto al comercio internacional defendían el librecambismo, excepto para la saca de vituallas que expresamente se prohibía, y en el mismo sentido se derogaban las marcas aplicadas a los 'navíos extranjeros' que las introdujesen en el Señorío. Sabino AGUIRRE GANDARIAS, Relaciones internacionales de Bizkaia con la Europa Atlántica medieval, "Revista internacional de Estudios Vascos", 36/2 (1991), pp. 339-363. En concreto p. 349). José Luis ORELLA UNZUÉ, Los vascos y sus relaciones mercantiles con Francia: Gascuña y Aquitania (siglos XV-XVI), "Itsas Memoria. Revista de Estudios Marítimos del País Vasco", 5 (2006), pp. 567-601. En concreto p. 587, para el caso de la reclamación de Lequeitio. Por lo que respecta a las relaciones con Inglaterra vid. Julián Antonio PRIOR CABANILLAS, Un caso de derecho internacional privado de finales del siglo XV: una Real Ejecutoria de la Chancillería de Valladolid sobre el comercio del pastel, "Cuadernos de Historia del Derecho", 10 (2003) pp. 345362. En el plano mercantil, Guipúzcoa pasaba a ser la puerta privilegiada para el comercio entre Castilla e Inglaterra, ya que se declaraba libre el tráfico y la estancia de mercaderes en uno y otro 
Una situación no exactamente idéntica se produciría en Galicia ${ }^{13}$. Así, integrantes de la misma señoría reaccionaban de manera heterogénea, ante un problema semejante, a causa de circunstancias diversas. En el fondo estaba también un, apenas disimulado, interés por parte de príncipes y señorías, por arrebatar competencias a comunas y elementos feudales soberanos o quasi soberanos durante la Edad Media ${ }^{14}$.

A lo largo del último cuarto del siglo XIV, algunos teóricos del derecho comenzaron a contemplar la vieja disposición latina, que impedía las pignoraciones forzadas, en represalia por acciones ilegales, desde otro punto de vista distinto de una hermética condena. En efecto, fruto de la que sin duda era una corriente de opinión muy extendida, será, precisamente, un italiano el que de el paso teórico más importante, al hacer compatible el buen derecho con una realidad que venía, imperturbablemente, cambiando lo pernicioso de las confiscaciones indiscriminadas por otro planteamiento mucho más lógico y positivo para las represalias. Se trataba de Giovanni da Legnano y su Tractatus de bello, de represaliis et de duello, redactado alrededor de 1375 o 1376. Con anterioridad, sin embargo, otros juristas ya habían identificado no solamente el problema sino también la forma de resolverlo ${ }^{15}$. De este modo, se sancionaba, desde el punto de vista de la ortodoxa teoría judicial, lo que la costumbre y los usos tradicionales venían realizando desde tiempo inmemorial. La justicia, en la opinión popular, consistía en hacer extensible determinados delitos a todos los súbditos de una señoría, con el simple propósito de poder hacer pagar a delincuentes, que pretendían salir impunes, y resarcir a víctimas que habrían sufrido el desamparo de la ley.

Podemos, por lo tanto, exponer ya aquello que es o puede definirse como marca o represalia. Existen algunos textos que nos ilustran sobre la naturaleza jurídica de estos términos ${ }^{16}$. No obstante, hay que tener presente que existe una cierta

país, suspendiéndose las tradicionales marcas de represalia cuyo empleo era reflejo de la política de carácter agresivo que se había seguido durante el periodo anterior de supresión de marcar, p. 347.

${ }^{13}$ Alfredo ERIAS Martínez y José Ma VeIGA Ferreira, Betanzos y su provincia en la época del Emperador Carlos V, “Anuario Brigantino", 25 (2002), pp. 181-260, en concreto pp. 192 y 196.

14 “À doutrina afirmada pelos teóricos da exclusiva titularidade do direito de conceder represálias por parte do princeps corresponderam, no campo dos fatos, os esforços dos sumos imperantes para privarem de faculdade de as outorgar os grandes feudatários, os organismos municipais e profissionais, parlamentos e até simples senescais reais, de forma a imporem o princípio de que só por autoridade régia eram as represálias praticáveis - não apenas devido aos evidentes perigos que representava nos domínios das relações internacionais a posse do direito de conceder represálias por aquelas entidades, como pelo prejuízo acarretado internamente à unidade política e ao princípio da soberania. Além das constantes lutas e da insegurança nascida das represálias e contra-represálias praticadas no interior de reino, faculdade de conceder represálias permitia, como resulta das construções doutrinais, negar a existência de um superior e sustentar a qualidade de soberano" (Ruy Manuel de AlBUQUERQUE, As represalias, p. 853).

${ }^{15}$ Jasonne Grabher O'BRIAN, In defense of the Mystical Body: Giovanni da Legnano's Theory of Reprisal, "Roman Legal Tradition", 1 (2002), pp. 25-55. Por lo que se refiere al texto, citado por O'Brian, de Legnano vid. Giovanni da Legnano, Tractatus de bello, de represalias et de duello, en The Classics of International Law Series, 8 (Editado por E. Holland), Oxford, 1917. Hay una reimpresión moderna en Buffalo, 1995. Sobre la obra de este jurista vid. G. ERMINI, I Trattati della Guerra e della Pace di Giovanni da Legnano in Studi e memorie per la storia dell'Universita di Bologna. $1^{\text {a }}$ series, VIII, Bologna, 1924, pp. 111-112. Otros trabajos académicos del siglo XIV habían contemplado parcialmente o desde una postura no tan definida las ideas de Legnano. Vid. Bartolus de SAXOFERRATO, Tractatus represaliarum en Consiliarum Bartoli, libri duo (1354), Lyon, 1555, ff. 125r-131r. Igualmente hay que tener en cuenta el Commentarium de Statutis, libri quatuor, I, q. 53a y De represalliis, en Tractatus universi iuris, 2, publicado en Venecia en 1584.

${ }^{16}$ Una buena definición puede ser la que considera que las represalias: "exerxiam-se contra inimigos, contra amigos ou simpatizantes de inimigos, contra neutros, contra compatriotas de um culpado ou de um devedor insolvente, etc. Implicavam destruições e mortes mas, sobretuto, confiscos de 
pluralidad de criterios o enfoques respecto de lo que se puede entender como represalia. Efectivamente, si buena parte de los historiadores del derecho contemplan este fenómeno como un conflicto, que en su esencia es comercial, mercantil, también puede entenderse como un procedimiento para distinguir entre piratería y guerra de corso. Así, algunos estudiosos vinculan las marcas con la voluntad de la alta política de señorías o monarcas, como una forma de ordenar sus intereses internacionales, de acuerdo con principios de guerra irregular, pero dejando al margen la piratería ${ }^{17}$. Desde nuestro punto de vista resulta inconveniente hacer uso del concepto nación o nacionales, cuando estamos hablando de señorías plenamente medievales y por lo tanto distantes de las revoluciones burguesas, cuando aparecerá la ideología y la doctrina nacional. Hacer mención del concepto nación o nacionales, cuando hablamos de señorías anteriores al antiguo régimen, es impropio y confuso.

En cualquier caso, muchos de los países mediterráneos y adyacentes han contado con buenos investigadores que, casi de manera homogénea, han tratado el tema de las represalias con solvencia. Los más veteranos fueron los franceses, que han desarrollado la curiosidad por el tema desde mitad del siglo XIX hasta mediados del XX, aproximadamente; pero también hubo italianos y portugueses, que se preocuparon por la cuestión a finales del siglo XIX y primera parte del veinte, los primeros, y en la parte central de esta centuria los segundos ${ }^{18}$. A parte de los

bens, prisões e fixações de residência, embargos ao comérço e à livre circulação, etc. Constituíam, moitas vezes, prelúdios a conflitos declarados o prolongamentos desses mesmos conflitos. Davam lugar a abusos frequentes, cometidos quer em terra quer no mar, por "engano" quanto à identidade do objeto da represália. O direito de represália era, por vezes, concedido por diploma régio, por exemplo una "carta de marca" que garantia ao capitão de um navio imunidade no ataque a navios inimigos uo para-inimigos e no confisco dos respetivos bens. Em contrapartida, "seguravam-se" navios estrangeiros contra tais apreenções, garantindo-lhes segurança” (A. H. De OLIVEIRA MARQUES, As relações diplomáticas, en Actas das II Jornadas Luso-Espanholas de História Medieval, vol. I, Porto, 1987, p. 57).

17 "La historiografia recent, malgrat que subratlla la impossibilitat d'una diferència de significat entre pirateria i cors, ha intentat no obstant això de posar limitacions entre els dos conceptes, especificant la base de tal distinció essencialment en la carta de marca o represàlia, la qual, concedida pel sobirà i justificada per la incapacitat de l'Estat de rescabalar els danys soferts pels seus súbdits, permetia al segle XV de realitzar personalment accions de pirateria autoritzada contra els països que havien causat el dany, si abans no s'havia arribat a un acord pecuniari. Així, doncs, la represàlia garantia els mercaders particulars contra pèrdues eventuals, i alhora permetia un control més gran de les autoritats públiques sobre les empreses particulars, a més de tendir a orientar els intents particulars en una única direcció, la lluita contra els enemics del rei" (Anna UNALI, Mariners, pirates i corsaris catalans a l'època medieval, Barcelona, 1986, pp. 141-142).

${ }^{18} \mathrm{El}$ libro de René de MAS LATRIE, Du droit de marque au droit de représailles au Moyen Âge, París, 1875, 123 pp. Editado inicialmente en "Bibliothèque de l'École des Chartes", 27 (1866), pp. 529-577, 29 (1868), pp. 294-317 y pp. 612-635. Sobre el caso concreto de Marsella vid. Guillaume-Marie-Joseph EIGLIER, Étude historique sur le droit de marque ou de représailles à Marseille aux XIIIe, XIVe et XVe siècles, Marseille, 1888. Cierta popularidad tuvo el siguiente trabajo de André Haumant, Les représaille, Paris, 1934, 224 pp. Con diferencia el más moderno es juntamente con el de Mas Latrie el que ha recibido más atención. Pierre-Clément TIMBAL, Les lettres de marques dans le droit de la France médiévale, Bruxelles, 1958. En concreto dentro de la colección Recueil de la Société Jean Bodin, L'Étranger, 10. El primero de los italianos sería Alberto del VECCHIO, Le rappresaglie nei comuni medievali e specialmente in Firenze, Bologna, 1894. XLV + 417 pp. Hay ediciones facsímiles de 1974 y 1984 como mínimo. Otro texto más reciente es el de Giovanni Italo CASSANDRO, Le reppresaglie e il fallimento a Venezia nei secoli XIII-XVI, Torino, 1938. Hay una edición más moderna de 1970. Por lo que se refiere a los investigadores portugueses vid. Ruy Manuel de Albuquerque, As represalias. Estudo de História do Direito portugués (sécs. XV e XVI), Lisboa, 1972, 2 Vols. También Luis Miguel DuARTE, Crimes do mar e justiça da terra, "Revista de Facultade de Letras. Universidade do Porto. História”, II serie, vol. VIII (1991), pp. 43-73. 
lusitanos, serán historiadores catalanes quienes más profundamente se hayan interesado por este aspecto en la península Ibérica, de hecho, se rastrea su interés desde comienzos del siglo pasado y se prolonga durante toda la centuria ${ }^{19}$. Al margen de este fenómeno de las marcas, promovidas por actos de guerra de corso, hay otras evidencias que nos hablan sobre conflictos, lógicos en zonas limítrofes, entre los vecinos de uno y otro lado de la frontera. Estas marcas o represalias fronterizas, podríamos decir menores, locales, vecinales, menudearon, por ejemplo entre las tierras de Castilla y Aragón ${ }^{20}$. Además, encontramos también litigios interiores entre poblaciones de una misma señoría, que podían acabar generando un gran conflicto de orden público, como las bandositats, en buena medida.

Al margen de esto, en el acervo historiográfico del ámbito territorial catalanoaragonés encontramos una disimetría llamativa. Por regla general, las informaciones de que disponemos tratan de referencias circunscritas a acciones protagonizadas por súbditos de la Corona de Aragón, que sufrirán el marcaje por parte vasallos de señorías vecinas. En este sentido resulta evidente pensar que las informaciones de que disponemos son más de reclamaciones extranjeras que no peticiones de represalias y procesos de evolución de las mismas, propias de súbditos catalanoaragoneses. Desde luego, sabemos que existieron acciones hostiles contra mercaderes de la señoría del rey de Aragón, pero no nos consta mucha información relativa a aquellos hechos o a las circunstancias en las que se produjeron y que se refieran también a cuestiones de marcas $^{21}$. Probablemente, las razones de todo eso tienen que ver con la agresividad de la política exterior de la señoría del rey de Aragón, desde finales del siglo XIII, y a los encontronazos del expansionismo comercial catalán por el Mediterráneo occidental, contundencias que tuvieron, entre otras secuelas, la de la acre rivalidad con potencias como Francia, territorio próximo y comercialmente competidor. La fijación de imposiciones, por otro lado, contribuyó a ensayar fórmulas fiscales de recauda-

${ }^{19}$ Joaquim MiRET I SANS, Les represàlies a Catalunya durant l'Edat Mitjana, "Revista Jurídica de Catalunya", 31 (1925), pp. 289-304 y 385-417. Josefina MuTGÉ VIVES, La marca de Bernat Melhac, la Corona catalanoaragonesa i el Llenguadoc (1327-1336) en XIIe Congrès d'Histoire de la Couronne d'Aragon. Montpellier, 1985. Vol. I (1987), pp. 175-188. También en "Anuario de Estudios Medievales", 16 (1986), pp. 227-238. EADEM, Una marca francesa contra els catalans, provocada per Francesc Carròs (1323-1335) en Homenatge a la Memòria del Prof. Dr. Emilio Sáez, Barcelona, 1989, pp. 127-138. EADEM, La inseguretat en el Mediterrani medieval. Acord entre el rei catalanoaragonès Pere el Cerimoniós i el francès Joan II de Valois (1351) per a la solució de les marques existents entre ambdós regnes en La Corona catalanoaragonesa i el seu entorn mediterrani a la Baixa Edat Mitjana, Barcelona, 2003, pp. 185-203. EADEM, Dos ejemplos de negociación de la época del rey catalana-aragonés Alfonso el Benigno (1327-1336) en Negociar en la Edad Media / Négocier au Moyen Âge (Maria Teresa FerRer MALlol, Jean-Marie MoEglin, Stephane PÉQUIGNOT y Manuel SÁNCHEZ MARTÍNEZ, eds.), Barcelona, 2005, pp. 527-551.

${ }^{20}$ Máximo DiAgo HeRnANDO, Introducción al estudio del comercio entre las coronas de Aragón y Castilla durante el siglo XIV, las mercancías objeto de intercambio, "La España Medieval", 24 (2001), pp. 47-101. En concreto podemos encontrar marcas locales entre poblaciones en pp. 58, 72-73, 83, 85, 93-94 y 97. Acciones de represalia en pp. 50, 52, 57 y 89.

21 "Siete años después de los hechos, producidos en 1336, el gobernador de Mallorca comunica al rey de Sicilia que se ha constituido una marca para satisfacer la parte todavía no satisfecha de lo robado por Marino Coxe, almirante de 15 galeras a sueldo de Sicilia, que había asaltado una nave cargada con alumbre, oro y especias -valorado en 23.291 florines de oro- de mercaderes mallorquines que habían cargado en las partes de Romanía para llevarlas a Flandes", Antonio ORTEGA VILLOSLADA, Las relaciones marítimo-comerciales entre el Mediterráneo y el Atlántico. El papel de Mallorca en el comercio entre Oriente y Occidente Siglos XIV y XV, en VIII Congreso de la Sociedad Española de Historia Económica, Santiago de Compostela, 2005, 34 p. en concreto p. 29. www.usc.es/estaticos/ congresos/histec05/b24_ortega_villoslada.pdf [consulta: 15.05.2008]. Vid., también del mismo autor: El reino de Mallorca y el mundo Atlántico (1230-1349), La Coruña, 2008. 
ción, que tendrán una enorme importancia en un inmediato futuro. La posibilidad de aprovechar la capacidad recaudatoria privada de los mercaderes afectados servirá a las instituciones medievales para consolidar una eficacia recaudatoria que les faltaba absolutamente pero que no surgió de repente ${ }^{22}$.

\section{LOS LLIBRES DE L'ART DE LA MERCADERIA COMO APLICACIÓN JURÍDICA}

El caso en el que se vieron envueltos el armador y patrón Pere Dezpuig, y su socio y escribano de nao Guillem Domingo, por un lado, y la compañía comercial de Bernat Valldaura y Domingo Aznar, por otro, nos permitirá constatar el funcionamiento de las marcas desde el punto de vista de los súbditos siniestrados de la Corona de Aragón.

En otro orden de cosas, hay una singularidad que hemos de resaltar. Sabemos de muchas de las circunstancias de este caso gracias al supuesto Libre de l'Art de la Mercaderia de Bernat Valldaura. Probablemente, este texto se conservó debido, primero, a la continuidad de las anotaciones llevadas por Domingo Aznar, en calidad de socio de Bernat y tutor de los huérfanos de Valldaura y procurador de los derechos de su viuda, y después debido a la necesidad de los herederos del difunto Valldaura de avalar, con testimonios fehacientes, sus reclamaciones respecto de la gestión de Aznar. Eso significó agregar, como pruebas y evidencias, páginas enteras de aquel registro del mercader difunto, elemento fundamental para entender la conservación de informaciones referidas a la represalia contra franceses, que reclamaron los siniestrados. Por deducción, cabe considerar que si no es frecuente encontrar informaciones relacionadas con marcas contra extranjeros, en la Corona de Aragón, ello podría estar vinculado con el hecho de que ese tipo de informaciones se gestionaba en administraciones distintas, propias de otras señorías, o porque las fuentes documentales disponibles en la Corona de Aragón serían, al margen de otras, los libros de mercaderes, raros y no suficientemente analizados.

Efectivamente, desde luego, sabemos que existieron a lo largo del siglo XIV y además menudearon entre algunos de los sectores mercantiles, aunque no es sencillo el encontrarlos ${ }^{23}$. De este modo, la primera cuestión a la que hemos de enfrentarnos es una cuestión de terminología: la diferencia, no siempre bien establecida, entre los libros destinados a las cuentas y su seguimiento, por parte de los mercaderes, y los libros destinados a la mejora de la técnica mercantil o de informaciones vinculadas con los negocios. Sin olvidar los libros de cuentas de instituciones públicas como comunas o gremios, por ejemplo ${ }^{24}$. Probablemente las versiones más

\footnotetext{
${ }^{22}$ María José CARBOnell Boria y Andrés DíAz BorRÁs, Determinación y definición de cuentas de las Cortes de 1329 en 1332. Antecedentes de la Generalidad Valenciana. La fiscalidad territorial y las imposiciones locales, "Anuario de Estudios Medievales", 34/2 (2004), pp. 713-745.

${ }^{23}$ Torres i Cortina no ha encontrado libros de mercader propiamente dichos en el registro de todos los hallados en el archivo comarcal de Manresa, por lo que deduce que no debieron de existir, por más que los comerciantes manresanos estuvieran capacitados para leer y escribir textos, a lo largo del trescientos, y de hecho llevaran registros de sus negocios. Miquel TORRES I CORTINA, L'escriptura i el llibre a la Catalunya Central als segles XIII $i$ XIV, tesi doctoral, Universitat Autònoma de Barcelona, pp. 2 y 39.

${ }^{24}$ Antonia BoRlAnd, Il manuale di mercatura di Saminiato de’ Ricci [1396], Génova, 1963, 181 pp. (Fonti e Studi, IV). Cesare CIANO, La Pratica di mercatura datiniana (Secolo XIV) (Con presentazione di Federigo Melis), Milano, 1964, 254 pp. (Biblioteca Della revista Economia e Storia, 9). Raffaele CIASCA, L'arte dei Medici e speziali nella storia en el commercio Fiorentino del secolo XII al XV, Firenze, 1927, 811 pp. (Biblioteca Storica Toscana). Benedetto CotrugLI, Della mercatura
} 
antiguas de los libros de negocios de mercaderes sean aquellas más parecidas a las de nuestra fuente.

Las primeras insinuaciones de la existencia de libros de cuentas, en la Corona de Aragón, corresponden a las ciudades de Barcelona y Mallorca, alrededor de $1275^{25}$. El primer libro de cuentas abarca al período 1304-1322, pero se trata de un registro público del cobro de la imposición sobre mercadería pisana en Ma1 lorca ${ }^{26}$. Un poco posterior es el primer registro de cuentas de mercaderes, manuscrito que fue formándose gracias a los negocios de los miembros de la Compañía Mitjavila, sociedad familiar que negociaba, prácticamente, con los tres continentes conocidos: Flandes, Sicilia, Cerdeña, Nápoles, Chipre, Beirut y Alejandría ${ }^{27}$. Estos escritos y otros posteriores han contribuido a formar la impresión de que la contabilidad, en los territorios peninsulares, se había organizado rápidamente y había adquirido una estructuración hasta cierto punto pionera en el ámbito europeo. No obstante, es innegable que no hay muchos estudios que nos ilustren sobre la existencia de libros de cuentas de mercaderes ${ }^{28}$. Por esa razón puede resultar estimu-

e del mercante perfetto, libri quattro, Venecia, 1573. Giorgio di Lorenzo CHIARINI, El libro di mercatantie et usanze de' paesi (Franco BoRLANDI, ed.), Torino, 1936, 212 pp., (Colección Documenti e Studi per la storia del commercio e del diritto commerciale italiano, pubblicati sotto la direzione di Federico Patetta e Mario Chiaudano,7). Édouard ForEstí́, Les livres de comptes des frères Bonis, marchands montalbanais du XIVe siècle, Paris et Auch, 1890-1894, 3 vol. (Archives historiques de la Gascogne; ser. 1, v. 20, 23, 26). Miguel GuAL CAMARENA, Un manual catalán de mercadería (1455), "Anuario de Estudios Medievales", I (1964), pp. 431-450. Miguel GuAl CAMARENA, El primer manual hispánico de mercadería (siglo XIV), Barcelona, 1981. Roberto S. LóPEZ, Un texte inédit: le plus ancien manuel italien de technique commerciale, "Revue Historique" CCXLIII (1970), pp. 67-76. José María MADURELl MARIMÓN, Contabilidad de una compañía trecentista barcelonesa (1334-1342), “Anuario de Historia del Derecho Español”, XXXV (1965), pp. 421-525, y XXXVI (1966), pp. 457-546.

${ }^{25}$ E. HeRnÁNDEZ Esteve, Orígenes y desarrollo de la contabilidad en España, siglos XIII-XIX, en J.A. GonZalo Angulo (a cargo de), Contabilidad en España. Madrid, 1992; también hay versión en inglés: Origins and development of accounting in Spain (from the 13th to the 19th century), in J. A. Gonzalo Angulo (a cargo de), Accounting in Spain, Madrid, 1992.

${ }^{26}$ T. AnTONI, I "Partitari” maiorchini del Lou dels Pisans relativi al commercio dei Pisani nelle Baleari (1304-1322 e 1353-1355), Pisa, 1977.

27 J. M. MADURELl I MARIMON, Contabilidad de una compañía mercantil trecentista barcelonesa (1334-1342), Madrid, 1966.

${ }^{28}$ Amedeo LEPORE, Sulle origini, sull'evoluzione e sullo statu dell'arte della Storia della Contabilità in Spagna, "De Computis, Revista Española de Historia de la Contabilidad", 3 (2005), pp. 33-71. En concreto vid. pp. 38-39. "Per quanto riguarda la fase "premoderna" - nell' arco di tempo che va dal XIII al XV secolo -, pur risultando l'esistenza di vari libri contabili e di talune disposizioni legali, non viè traccia di alcun trattato o testo dottrinale sulla materia. Le prime notizie di sistemi contabili e libri dei conti si riferiscono alla Corona di Aragona e, in particolare, alla Catalogna e a Maiorca ( $c f r$. Hernández Esteve, 1992a): a cominciare dal 1275, infatti, i banchieri di Barcellona utilizzarono un nuovo sistema contabile, che solo nell'aspetto esteriore e nei libri impiegati si avvicinava alla partita doppia, senza però rispettarne le regole, fornire un quadro complessivo dei conti e assicurare la corrispondenza tra le diverse forme contabili (cfr. Conde y Delgado de Molina, 1988). Il primo libro dei conti conosciuto in Spagna era un registro pubblico di Maiorca (1304-1322), relativo al controllo del pagamento di imposte per l'entrata e l'uscita delle merci, denominato "Lou dels Pisans" ( $c f r$. Antoni, 1977). Altri libri contabili dell'epoca erano quelli della compañía "Mitjavila” (1334-1342), che si dedicava all'esportazione e all'importazione con le Fiandre, la Sicilia, la Sardegna, Napoli, Cipro, Beirut e Alessandria ( $c f r$. Madurell i Marimon, 1966). I libri della "Taula de Canvi" di Barcellona ( $c f r$. Adroer i Tasis e Feliu i Montfort, 1989), il primo banco pubblico fondato in Europa (1401), pure assomigliavano esteriormente alla partita doppia, ma non ne facevano realmente uso. Le prime regolamentazioni dei libri contabili ( $c f r$. Envid Miñana, 1985), della loro tenuta e della professione contabile si possono rinvenire nel 
lante la publicación de los documentos, un par de asientos de un hipotético libro de mercadería, que habría confeccionado un comerciante, que vivió en la primera mitad del siglo XIV.

No queremos concluir esta parte del estudio sin hacer una mención especial a la, a nuestro juicio, cualidad transversal de la información que hacemos pública. En efecto, si hay algo que en un principio llamó nuestra atención eso fue la plurifacética interpretación del proceso. Por un lado, podía ser analizado desde el punto de vista de un acto de corsarismo ilegal y la marca que ese latrocinio llevó consigo. También llama la atención la singularidad del libro de mercader, que parece estar en el centro de buena parte de la polémica del pleito. Pero es que, además, y ahí el remate de la transversalidad de la fuente, hace referencia a la gestión económica del resarcimiento por la marca. Efectivamente, el documento en cuestión también abordará la clave del dinero que Domingo Aznar, quizás de manera un tanto discutible, consiguió del resarcimiento de la marca contra franceses. Ese dinero se recaudó, aquí está lo más significativo, mediante la organización simple de una red privada de recolectores del dinero, previamente fijado por las autoridades francesas y de la Corona de Aragón. Es llamativa esta organización, pluriterritorial, dentro de la señoría de la Casa de Barcelona, porque ilustra bien a las claras la capacidad organizativa y su efectividad a la hora de establecer entidades recaudatorias complejas. Parece claro que en la primera mitad del siglo XIV la madurez financiera de los territorios de la Corona de Aragón, en concreto del reino de Valencia, era suficiente como para acometer una empresa como esta, o por mejor decir, que para organizar una empresa como esta no era necesario una muy estructurada red de control aduanero ${ }^{29}$. Esa constatación simple sirve para ser aplicada en casos paralelos, para los que demostraría la gran capacidad de gestión económica, con la que estaban dotados los negociantes medievales, pese a que sus problemas de organización financiera a nosotros nos puedan parecer mucho más complicados de lo que, en realidad, lo fueron para ellos.

“Código de las Siete Partidas", promulgato da Alfonso X el Sabio nel 1265 ( $c f r$. Martínez Marina, 1834; Hernández Esteve, 1985a); nel "Llibre del Consolat de Mar" di Barcellona e in quello di Valencia ( $c f r$. Colón Domènech e Garcia i Sanz, 2001; Ferrando, Gisbert e Crespi, 1977), i cui nuclei originali possono essere fatti risalire all'epoca tra la fine del XIII e l'inizio del XIV secolo, anche se la loro redazione definitiva va collocata tra la fine del XIV e il principio del XV secolo; nel "Llibre de les Costums de Tortosa" del 1272 ( $c f r$. AA.VV., 1979; Duarte i Montserrat, 1985; Massip Fonollosa, Duarte i Montserrat e Massip i Bonet, 1996); nel "Cuaderno de Alcabalas", emanato dai re cattolici nel 1484, con l'intento di imporre ai commercianti la tenuta di un libro dei conti riguardante le loro operazioni, per fini fiscali e di controllo ( $c f r$. Mendoza Díaz-Maroto e Pretel Marín, 2001)". Es igualmente muy ilustrativo de las dificultades que encuentran los historiadores, para hallar fuentes interesantes y mínimamente copiosas, el libro de Enrique CRUSELLES GómEZ, Los comerciantes valencianos del siglo XV y sus libros de cuentas, Castelló de la Plana, 2007. Es un trabajo completo que aborda en un tono aceptable este problema en Valencia. Además de la prolija y documentada introducción referente a los libros de cuentas en la Europa medieval, hace mención de algunos textos del cuatrocientos, vid. especialmente, pp. 96 y ss.

${ }^{29}$ Vid., por ejemplo: Andrés DíAZ BORRÁs, La primera operación de censales realizada por la ciudad de Valencia (1350-1356). Un hito documental para la historia de la financiación comunal, en Actas del II Congreso de Jóvenes Historiadores y Geógrafos, Valencia (1993), pp. 111-116. IDEM, Un intento de aproximación a la hacienda local de la Alzira medieval. El Inventari dels béns de la Universitat (1380), "Al-Gezira", 8 (1994), pp. 179-224. 


\section{PiRATERÍA Y REPRESAlia: El ASALto A la COCA SANT NiCOLAU}

La nave, coca o carraca, llamada Sant Nicolau, habría cargado mercancías variadas en el Grau de Valencia con destino a Lisboa y la ruta de Galicia ${ }^{30}$. De la nómina de lo robado se desprende que los bienes abarcaban una panoplia de productos manufacturados del Mediterráneo y algunas mercancías probablemente no de gran lujo pero sí suntuarias. De la nómina de lo robado se desprende que habría textiles, loza simple, especias comunes, y otros productos variados ${ }^{31}$. Por la composición de lo robado no podemos presumir una cosa distinta de que el propósito de los comerciantes, transportando mercancías de fácil venta y una rentabilidad no excesiva pero suficiente, era el de introducirse en la ruta de Poniente, donde el comercio valenciano todavía no estaba bien arraigado y pugnaba por abrir mercados ${ }^{32}$. Efectivamente, el intento de afianzamiento de la presencia valenciana en Lisboa, por ejemplo, parece el paso previo y obligado para el arribo a los activos puertos del Canal de la Mancha, región con la que los lazos mercantiles de la ciudad del Turia, aunque en precario, existían y podían ser agrandados. Los intentos de apertura de nuevas plazas para el negocio valenciano no dejaron de producirse, bien es cierto que las dificultades, en todas partes, fueron grandes ${ }^{33}$

De este modo, en el mes de abril, de 1347, la coca, surta en las playas de la capital, estaría lista y a punto para iniciar su travesía, habiendo sido cargadas sus

${ }^{30}$ Antonio ORTEGa VILlosladA, La coca en el intercambio mercante Atlántico-Mediterráneo, "Anuario de Estudios Medievales", 38/1 (2008), pp. 429-444.

${ }^{31}$ Se hicieron tres inventarios de bienes robados, probablemente bienes compartidos en los tres inventarios y otros que no lo fueron. Cada inventario correspondía a uno de los partícipes en la carga del barco. Se trata de Domingo Aznar, Pere Dezpuig y Guillem Domingo, sobre ellos hablaremos más tarde. AMV, Judiciarii, pp-4, mà $2^{\mathrm{a}}$. Respectivamente ff. $29 \mathrm{v}-30 \mathrm{r}$ para el primero, f. 30rv para el segundo y f. 30v para el tercero. Como decimos, las mercancías saqueadas eran las típicas de los mercados secundarios del Mediterráneo. Se robaron alimentos, sin duda, comida propia de los mercaderes que emplearían para su propio uso y tal vez para su venta en algún puerto, si los precios les resultaban atractivos: harina, aceite, tocino y queso se repiten insistentemente en los inventarios. Además, se registraron productos de un mayor precio, canela, azúcar blanca y candí. En el campo de los textiles, la variedad es enorme. Desde productos escasos como seda, oropeles, hasta telas valencianas, de Perpinyà, de lino, algodón, en formas y tipos variados. En alguna ocasión se anotaron productos de loza al estilo malagueño o productos para el consumo como tamboriles y panderetas. Siempre en el lote de Aznar. Casi todos llevaron mercancías de hierro y plomo y, por supuesto, armas y elementos del barco fueron requisados, siendo la variedad considerable. Significativo es el hecho de que aparezcan elementos básicos para la navegación por estima: papa mundo, cannes de bruxo y bruxola. Estos elementos, frecuentes en la navegación de la época, lo eran menos en los trayectos de cabotaje cortos, propios del Mediterráneo.

${ }^{32}$ Probablemente, el tráfico con Portugal no llegó a regularizarse nunca, como parece demostrarse por los trabajos de José Hinojosa MonTAlVo, De Valencia a Portugal y Flandes, relaciones durante la Edad Media, "Anales de la Universidad de Alicante. Historia Medieval", 1 (1982), pp. 149-168. De igual manera la presencia portuguesa en Valencia también concluyó generando un decaimiento significativo a lo largo del siglo XV, como consecuencia de la instauración de una especie de marca local conocida como dret portuguès. Andrés DíAZ BORRÁs y José TRENCHS ÒDENA, El fracaso de la expansión portuguesa en el Mediterráneo a través de la documentación valenciana (1450-1500), "Estudis Castellonencs", 4 (1987-1988), pp. 375-440. IDEM, Piratería y Dret Portugués: el ocaso lusitano en Valencia durante la transición del Mediterráneo al Atlántico (1450-1500), en Congresso Internacional Bartolomeu Dias e a sua Época. Actas III. Economia e comércio marítimo (Porto, 1989), pp. 405-435.

${ }^{33}$ Rafael CARIÑENA BALAGUER y Andrés DÍAZ BORRÁs, La ruta marítima Valencia-Alejandría y la promoción comunal de la construcción naval durante la Edad Media, en La construcción naval y la navegación: I Simposio de Historia de las Técnicas, Santander, 1996, pp. 441-452. 
bodegas. Probablemente, la nao zarparía del Grau a finales de mes o a comienzos de mayo, dedicándose al tráfico de cabotaje en los puertos antesala del Estrecho, es decir en tierras granadinas, donde las mercancías valencianas tenían cierto predicamento y era barato comprar productos de cierta calidad, raros al doblar el cabo de San Vicente, rumbo al norte ${ }^{34}$. En efecto, es probable, por ejemplo, que se adquiriera loza malagueña es este puerto o en alguno de los nazaríes, puesto que este tipo de cerámica aparece en la nómina de lo robado. Por fin, a finales de junio llegarían al límite de Poniente, poniendo rumbo hacia el norte. Una vez doblando el cabo de San Vicente, se encontraron con una escuadrilla de siete galeras, a sueldos del rey de Francia, que al mismo tiempo que los valencianos, pasaban al Atlántico, con objeto de reforzar las fuerzas que luchaban contra los ingleses. Al cambiar de bordada, las fustas, probablemente, amainaran en su navegar, con la esperanza de esperar y encontrar alguna nave que pudiera ser interceptada en unas aguas de obligado paso para todo el tráfico Atlántico-Mediterráneo. Entre el 22 y el 26 de junio tendría lugar el avistamiento, la aproximación y el abordaje de la carraca por tres galeras de la escuadrilla, las patroneadas por Manfré Malauzell, Joan de la Cava y micer Agustí de Castar ${ }^{35}$. Descubierta por la escuadrilla, dos galeras intentarían ponerse a babor y estribor, mientras que la otra le cortaba el viento por proa. Así las cosas, sin muchos argumentos defensivos esgrimibles y ante la insistencia de que amainaran en la marcha, la nao valenciana optó por obedecer, pecando quienes la gobernaban de ilusos. La coca, fue arriando trapo hasta quedar al pairo, para dejarse abordar pacíficamente, eso si, por los hombres de las galeras. Una vez a bordo, los provenzalo-genoveses reunieron a los oficiales de la carraca y les obligaron a pasar a las fustas, donde serían amenazados, vejados e insultados para amedrentarlos. De nada sirvió que se reiteraran, una y otra vez, en que ellos eran súbditos del rey de Aragón y que, por lo tanto, no había ningún contencioso con los súbditos del rey de Francia, estaban en paz y no existía litigio entre las partes. Los asaltantes procedieron a requisar cuanto quisieron y hallaron del barco y a llevárselo a sus galeras, sin que hubiese posibilidad de reacción por parte de los hombres de la coca. Sabemos todo esto gracias a las deposiciones y denuncia que fue interpuesta por los tres afectados ante las autoridades de Lisboa y por la declaración de testigos, marineros de la coca, que corroboraron las palabras de los implicados ${ }^{36}$.

Las bodegas de la carraca valenciana fueron llenadas con mercancías de la compañía de Bernat Valldaura y Domingo Aznar. Sabemos que para este viaje se había formado una sociedad, de la que se pretendían distribuir las ganancias, a partes iguales, entre Bernat de Valldaura y Domingo Aznar, por un lado, y Pere Dezpuig y Guillem Domingo, por otro. Estos dos eran el propietario y patrón de la coca, Dezpuig, y el escribano y socio del anterior, Domingo. Los primeros aportarían a la sociedad las mercancías, los segundos el barco. Ambas partes arriesgaban, seguramente, una porción similar de capital, por lo que se acordó que los beneficios se compartirían a partes iguales entre dos.

\footnotetext{
${ }^{34}$ Antonio OrTEga VILloslada, Viajes a Flandes e Inglaterra ¿Cabotaje o recta vía?, "Espacio, Tiempo y Forma, Serie III, Historia Medieval”, 16 (2003), pp. 229-249. Para este autor no será hasta 1312 cuando comiencen a aparecer buques redondos del Mediterráneo en el Atlántico. En concreto se trataría de barcos mallorquines. La presencia valenciana no está documentada antes de 1333, en concreto pp. 237-239.

${ }^{35}$ AMV, Ibidem, mà 2a $2^{\mathrm{a}}$,f. 29r-30v.

${ }^{36}$ Hubo hasta tres testigos que corroboraron las palabras de los mercaderes y patrones: el primero en deponer será Tomàs Miró, marinero de la coca. El segundo Guillem Dezpuig, también marinero de la coca, el tercero será Francesc Beldon, patrón de la coca Sant Joan de Mallorca, enrolado también en la tripulación de la valenciana, probablemente como marinero. El último será Guillem Català, también marinero de Mallorca. Vid. Sucesivamente AMV, Ibidem, mà 2a ff. 31r-33r, 33r-34v, 34v$35 \mathrm{v}$ y $35 \mathrm{r}$.
} 
Dentro de cada una de las dos sociedades, que participaban en el negocio, ignoramos que porcentaje de beneficios correspondería a cada uno de sus partícipes. Cabe que fuera una proporción idéntica, pero también es posible que no fuera así, que el propietario tuviera más parte de las ganancias y el escribano menos. En cualquier caso, parece evidente que dado que ellos ponían, básicamente, el barco y la dirección del viaje, su porción de mercancías sería casi residual en comparación con la de los otros socios, aunque los beneficios fueran los mismos.

En efecto, la parte de los bienes que correspondía a la compañía integrada por Valldaura y Aznar será la mayoritaria, puesto que ellos no arriesgaban la propiedad del barco. De nuevo, nos encontramos con un dilema. La participación de las ganancias podía ser a partes iguales pero tenemos sospechas de que eso no llegó a ser así. Cuando en Portugal se mencionará las pérdidas de los mercaderes valencianos se cita a Aznar, como afectado, pero no a Valldaura, dando la sensación de que éste no sufrió ninguna merma. Cabe una explicación para este hecho, Valldaura participaría en los beneficios, si los hubiere, pero no en las pérdidas, quizás porque Aznar estuviera en deuda con su socio y esta asociación tuviera como objetivo reintegrarle alguna suma de dinero de los beneficios. Eso explicaría que la pérdida, fruto del acto de piratería, solamente repercutiera en Aznar, que después tendrá que reclamar los ingresos de la marca contras franceses, pero no en Valldaura. No obstante, también se puede entender como que Aznar, único de los dos mercaderes a bordo, ostentara la representación de la compañía. De ese modo, cuando la fuente se refiere a Aznar, en realidad quiere mencionar a la compañía ${ }^{37}$.

Aunque en el pleito, entre la familia del difunto Bernat de Valldaura y Domingo Aznar, no se hace mención a que el primero no estuviera en la coca, cuando esta fue saqueada por los genoveso-provenzales y, por lo tanto, no sería uno de los que presentaron la reclamación ante el Alguacil de Lisboa, a través de la documentación portuguesa, se constata que no se hallaba en aquel país cuando tuvieron lugar los hechos. Fue, únicamente, Domingo el que presentó la reclamación, sin ninguna referencia a Bernat. De hecho, leyendo la documentación, puede parecer una treta, urdida por los abogados de la parte de la familia Valldaura, para restar credibilidad y acusar de usurpación del dinero de la marca, que correspondiera al difunto Bernat de Valldaura y que se habría apropiado indebidamente Aznar. El problema es irresoluble para nosotros, pero también debió serlo para los jueces medievales, que no hallaron instrumentos para esclarecer la verdad. Es posible que las mercancías robadas fueran casi en exclusiva de Aznar y que, por razones comerciales desconocidas, éste fuera a medias en las ganancias con Valldaura, pero evidentemente no sería así en las pérdidas, porque los bienes robados le pertenecían en exclusiva, esa será la postura de la defensa de Aznar. Cabe también que las mercancías fueran de las dos partes o, incluso, que la suya fuera la más cuantiosa, con lo que Bernat Valldaura tendría derecho a cobrar, no solamente de los beneficios obtenidos por su venta, sino también de las indemnizaciones cobradas, fruto de la marca. Esta sería la postura de la familia Valldaura.

El documento expedido en Lisboa dista mucho de aclarar semejante extremo pero es que tampoco es una marca, ni mucho $\operatorname{menos}^{38}$, no lo es por más que la fuente

${ }^{37}$ AMV, Ibidem, mà $2^{\mathrm{a}}$, f. $23 \mathrm{r}$.

${ }^{38}$ La primera parte es una denuncia en la que las tres autoridades fundamentales de la coca: Pere Dezpuig, Guillem Domingo y Domingo Aznar presentaban la denuncia ante la autoridad competente, de la jurisdicción portuguesa, el alguacil de Lisboa y se relataba lo acontecido en aguas del cabo de San Vicente. AMV, Ibidem, mà $2^{\mathrm{a}}$ f. 29rv. Después hallamos la relación de los bienes robados y sus propietarios: f. 29v y f. 30r para Aznar, de cuyos bienes "dizem que eram suas e que las fillaron os ditos genovesses e proençaes que andavam em ditas galees e que las fillavam por mandado dos 
valenciana insista en este sentido. Cabe, eso si, considerarlo como el inicio de un proceso, mucho más largo, gravoso, y complejo. No es una marca porque se presentó ante una instancia que no era afectada y, por lo tanto, no era parte actora en el pleito. Las autoridades portuguesas no podían interponer una reclamación ante el rey de Francia porque los hechos no se referían a súbditos de su señoría y el concepto de jurisdicción marítima, de aguas territoriales donde se ejerciera la potestad, faltaba siglos para que viera la luz. De este modo, lo único que se pudo conseguir, por parte de los valencianos, fue el reconocimiento de unos hechos, el levantamiento de acta de denuncia, una fedación testimonial de pérdidas, un reconocimiento objetivo de lo ocurrido, de naturaleza oficial. En este sentido si que el documento podría entenderse como el inicio del proceso que culminará en la concesión de los beneficios de la marca.

Efectivamente, una vez que habían alegado, las victimas, las pérdidas sufridas a manos de los genoveses y provenzales, las autoridades lusitanas procedieron a hacer las oportunas indagaciones, para constatar la veracidad de cuantas informaciones proporcionaron los siniestrados. Hemos visto más arriba como se contrastó la información vertida por lo mercaderes robados con las deposiciones de cuatro testigos presenciales, que se hallaban en la carraca en el momento de su apresamiento y saqueo. Una vez concluidas, el Alguacil de Lisboa se limitó a dar fe de la autenticidad de cuanto los siniestrados relataban, según acreditaron los testimonios, con el propósito de que sirviera de prueba ante previsibles futuras reclamaciones ${ }^{39}$.

\section{EL LIBRO DE LA MERCADERÍA DE VALLDAURA}

El impacto de lo sucedido, el previsible estado en que quedó la coca y la distancia entre cabo San Vicente y Lisboa hizo que Aznar y el resto de los implicados en el latrocinio no se presentaran ante el Alguacil de la capital hasta el primer día de septiembre $^{40}$. Entonces, probablemente aconsejados por otros mercaderes y gentes de mar, súbditos del rey de Aragón y las propias autoridades y marinos portugueses, les instarían a poner por escrito lo que habían padecido ${ }^{41}$. Con este documento redactado, ya sería factible presentarse delante de las autoridades de su propia señoría, el rey de

patrones das ditas galeras". El segundo en enumerar las cosas robadas fue el patrón de la galera Pere Dezpuig, que repetirá la fórmula de Aznar, f. 30rv. Por último enumerará las pérdidas Guillem Domingo, f. $31 \mathrm{r}$ con semejante coletilla final.

39 "Et entre si disseron por lo juramento que feto avian que as ditas cousas valian os ditos setecentos e XXX scudos douro e muyto mais e pedia a adito Aluazil que desse a mi dito tablion sui autoridade ordinaria por alli dar un strumento das ditas cousas. Et a major firmidade ho mandasen ser sellado do sello pendent da conselho de dita ciutade e o dito Alguazil mande a mi dito tablion e deu a mi su autoridade ordinaria per alhidar das dos ditas cousas in público instrumento". AMV, Ibidem, mà 2, f. 35 rv.

40 "Saben todos quan era de Mill trezentos ochenta quatro anos. Primo dia de setembro, en la cidade de Lisbona, no Adro de Sardas, d'esta cidade, en Conselho parlant Lorenço //f. 29v Andrés, Loctinyo, Alguazil General de la dita ciutade. Secundo oyendo os fechos em presencia de mi, Johan Lorenço, tablalion público de la dita ciutade e dos testigos, que adente son scritos, parlant o dito Alguazil comparescente Pere Dezpuig, maestre que se dizia de una carecha de Valencia a que xaman Sant Nicholau, de dito logo de Valencia, En Guillem Domingo, que se dizia quinhoeira da dita carecha, En Domingo Aznar, mercadero que se dezia de dito logo de Valencia, e quinhoneyzo da dita da dita carecha". AMV, Ibidem, mà 2a, f. 29 rv.

${ }^{41}$ En la deposición de los testigos estuvieron presentes, también, procuradores y escribanos, probablemente relacionados con los siniestrados. Los procuradores fueron: Alfonso Xanes, Joan Pereç, Joan Alhonegados, Giral Monteyro, Gil Matey y Gramel Xanes. Entre los escribanos se encontraban Alfonso Stévanez, Joan Pereç, Sanço Eanes y Pero Gago, entre otros. AMV, Ibidem, mà 2, f. 31r. 
Aragón, para iniciar la tramitación de la solicitud de una marca contra súbditos del rey de Francia. Eso ocurrirá el primero de febrero de 1348, cuando ante el Baile General de Valencia, comparecían los afectados y comenzaban a exponer lo sucedido, como pasó en Lisboa ${ }^{42}$.

Vamos a detenernos en este punto para verificar, cómo se planteó uno de los problemas nodulares del proceso, en el que hallamos todas estas informaciones. Vimos como todas las partes alegaron que las mercancías robadas pertenecían a Aznar, mayoritariamente, o a Valldaura, dependiendo de quien fuera el que hacía el alegato en el proceso y que eso era fruto de los convenios y sociedades que se habían estipulado entre las partes. Desgraciadamente no se pudo fundamentar, de manera adecuada, cuál de las partes tenía razón, pero es cierto que se intentó y se intentó mediante la aportación de copias, supuestamente fidedignas, del libro de mercader de Bernat de Valldaura. Eso nos lleva al segundo tema crucial de este trabajo, el de la competencia mercantil y la organización de las cuentas de mercantes valencianos.

Conocemos unos folios, autentificados por la administración, del libro de mercader de Valldaura, entre otras menciones. En efecto, se trata de una breve descripción de la obra: un libro de grandes dimensiones, grueso y con las tapas de pergamino blanco ${ }^{43}$. En el interior de este registro se halla un primer documento que resulta clave en todo el proceso judicial, es la constitución de una sociedad en la que, entre otros miembros, figura Bernat Valldaura y Domingo Aznar, que se encuentra en el folio setenta y cinco del libro de mercadería mencionado ${ }^{44}$.

"LXXV cartes.

En nom de Déu, e de la Verge Maria.

Refermam la Companyia N'Arnau de Pujamar e yo, en Tortosa, diumenge a XVIII de juny de l'any de Nostre Senyor M CCC XLVI. La qual rahó és segons que davall se segueix per menut, de MM C XXIX lliures $\mathrm{XV}$ sous IX diners mealla:

En la qual companyia ha, primerament, N'Arnau de Pujamar, segons que.s conté, en lo seu compte en LXXIIII cartes d'est llibre: DCCCC lliures.

Ítem, hi ha Bernat de Valldaura, segons que el seu compte és contingut en LXXIIII cartes: DCCCC lliures.

Item, hi ha En Domingo Aznar, segons que el seu compte és contengut en LXXIIII cartes: CCXLVIII lliures VIII sous VI diners mealla. Item, hi ha En Francesch Rovira, segons que el seu compte és contengut en LXXIIII cartes d'est llibre: LXXXI lliures VII sous III diners.

Tota la rahó és en poder de N'Arnau de Pujamar. De la qual sobredita se deu pagar la soldada d'En Francesch Ro-//38v qua. Són V lliures l'any e deu viure sobre la rahó.

\footnotetext{
${ }^{42}$ AMV, Ibidem, mà 2a , f. 28rv.

${ }^{43}$ AMV, Ibidem, mà 2a , f. 39v. "Les quals scriptures e comptes, damunt inserts e contingudes, foren tretes e en lo present procés traslladades per mi, Bartholomeu Vilalba, notari scrivà del present pleyt, de un libre gran de comptes, ab les cubertes blanques de pergamí, lo qual, lo dit En Pere d'Òdena, aferma e dix ésser d'En Bernat de Valladaura. E axí a pròpia prima faç, per letra de la scriptura de aquell, en lo qual libre eran scrites e contingudes les dites scriptures en comptes en diverses lochs".

${ }^{44}$ AMV, Ibidem, mà 2a , f. 38rv.
} 
Ítem, se deu pagar a Bernat de Valldaura, per un macip l'any: X lliures.

Ítem, se deu pagar a Bernat de Valldaura, per messió d'una bèstia l'any: X lliures.

Ítem, se deu levar, per mesió de un macip de N'Arnau de Pujamar: $\mathrm{X}$ lliures.

E levades les messions deu-se levar del guany, que Déus hi darà, lo dit diner e aquell deu-se parrar per terç. E la un terç deu haver N'Arnau de Pujamar, e l'altre terç Bernat de Valldaura e l'altre terç En Domingo Aznar, e lo sobre pus del guany deu-se partir per sou e per lliura. Feu la carta En Pere Sunyol de Tortosa".

El segundo de los papeles incorporado, como prueba testifical, corresponde a los asientos de gastos y dinero invertido en hacer el trayecto hasta el rey de Francia, con objeto de reclamar la tropelía. En esta ocasión la pormenorizada especificación de las cuentas se halla en los folios del libro de comercios de Bernat Valldaura ciento cuarenta y dos y ciento cuarenta y tres ${ }^{45}$.

\section{"CXLII cartes}

Deu-me la rahó, que era entre Nós e En Puig, que doní als misatgers que anaren al Rey de França per demanar ço que.s fo levat per los jenovessos que anaven a son sou en Frandes, per rahó de les mesions que.ls misatgers devien fer, les quals paguen los predecedents per la misatgeria lur a rahó de III lliures per C de lliures que munten a D LXXXIIII lliures, que Nós hi havíem menys de les mesions e han nom, la un misatger que és de Barchinona, En Guillem de Figes e l'altre que és de Mallorches, En Guillem de Térmens: $X$ sous.

Item, hi fem de messions en la carta de procuració que feu En Puig a.N Domingo Aznar: VI diners.

//f. 39r. Item, doní a.N Copons, per trellador la carta que.s feu a Lisbona de la requicisió XII sous.

Item, doní a.N Cardona scriptura del Batle, per metre lo treslat de la carta en libre e la requisició: XVI sous.

Item, doní a.N Domingo Gascó, per la requisició que ordena: II sous VI diners.

Item, doní a un saig que a dux lo procés de la Casa del Batle a Casa d'En Domingo Eymerich e.l me tornà: IIII diners.

Item, doní a.N Domingo Eymerich, assessor del Batle, per acordar la stima: I lliura.

Item, doní a.N Cardona, scrivà del Batle, per metre la stima en forma pública ab segell pendent: XVIII sous.

Suma per tot: XX lliures XV sous IV diners.

Axí que munta la roberia que.ns fo feta ab les messions que en València ne fem e ab les messions que.n fem a Lisbona, que són II lliures IIII sous [X diners], per tot munta DCVII lliures II diners, que valen en florins a raó de XII sous VI diners: DCCCC LXXI florí mig.

CXLIII carta.

${ }^{45}$ AMV, Ibidem, mà $2^{\mathrm{a}}$, ff. $38 \mathrm{v}-39 \mathrm{r}$. 
Deu-me la rahó, que bestraguí en messions de la averació de la roberia, segons que pus largament se comté en CXLII cartes de ço que costa la carta que aguem a Lisbona: X lliures XV sous X diners.

Deig yo, Bernat, a la rahó que era entre Nós e En Pere Dezpuig, los quals levam a tot lo comú per fer messions per rahó de la roberia que jenoveses nos feren, que anaven al sou del Rey de França: XX lliures.

\section{Modí aquesta carta en CLIII cartes."}

A través de todos estos segmentos, del supuesto texto de Valldaura, podemos distinguir que tipo de registro de géneros sería. Hay una triple división tradicional de los libros de cuentas: el memorándum, el de partida simple y el de partida doble. El primero sería el más rudimentario, una especie de pandemónium en el que el comerciante iba anotando, con suerte siguiendo un cierto orden cronológico, lo que podríamos decir que serían asientos de ingresos, gastos, etc. El memorándum la recopilación de textos más antiguos, los primeros libros del arte de la mercadería, se remontaría en el tiempo hasta, probablemente, comienzos del siglo XIV o incluso algunos años antes ${ }^{46}$. Le seguiría el libro de partida simple, que comenzará a dejar testimonio de su existencia en la segunda mitad del trescientos y no se extenderá hasta bien avanzado el siglo $\mathrm{XV}^{47}$. Por último, el libro por partida doble será un logro de finales del cuatrocientos y principios del quinientos, ya en la Modernidad. La partida simple permitirá diferenciar entre ingresos y gastos, eliminando asientos de otra índole. La doble o compuesta queda muy lejos de nuestras perspectivas y, por lo tanto, no haremos referencia a ella aquí.

De cualquier modo, lo que si es cierto es que el conocimiento de libros de mercader en la Valencia medieval se limita a algunos ejemplares de fechas ciertamente tardías. Cruselles menciona los de Andreu Conill, de 1420-21, Pere d'Amiga, 1458-66, y Onofre Ferrer, de 1498-1048. De acuerdo con estas reflexiones parece claro que el supuesto llibre de l'art de la mercaderia, de Bernat de Valldaura, correspondería al tipo de memorándum, pero probablemente con ciertas consideraciones que no corresponden a este modelo o patrón estricto y que implicarían o podrían implicar una evolución hacia la partida simple. Vamos a intentar explicarlo con los pocos datos de que disponemos, haciendo, a su vez, una breve reflexión sobre el contenido del documento.

${ }^{46}$ Enrique CRUSELLES GÓMEZ, Los comerciantes valencianos del siglo XV y sus libros de cuentas, Castellón de la Plana, 2007, pp. 21-22. "La teneduría de libros más rudimentaria se centra en el memorial o memorándum, donde el mercader registraba cronológicamente, con un estilo narrativo y sin ningún tipo de ordenación temática, todas las operaciones con las que abonaba o adeudaba cantidades a través de créditos. Las partidas acreedoras y deudoras se sucedían de manera indiferenciada, con un espacio en blanco destinado al registro de asientos complementario que compensaba la operación inicial, momento en el que cancelaba el asiento mediante una raya cruzada. Se trataba de un libro mamotreto por cuanto, junto a estas partidas, se registraban otras relacionadas con gastos domésticos, transacciones comerciales y, más tarde, operaciones de caja o inventarios".

${ }^{47}$ E. CRUSELLES GómEZ, Los comerciantes, p. 22. "La ampliación del volumen de las operaciones y el incremento de clientes y corresponsales provocó el aumento del número de cuentas y, sobre todo, implicó el agrupamiento que facilitara su identificación y clasificación. Por tanto, del memorial originario, que no desaparecía, comenzaron a desgajarse diferentes tipos de cuentas, primero personales, después de valores, como la de mercancías, y finalmente las operaciones de caja, dando lugar a una contabilidad empresarial más compleja integrada por un número cada vez mayor de libros. El principal avance permitido por esta contabilidad es el de la difusión del concepto de cuenta corriente y de la extensión de la idea de personalización a otras cuentas de valores: la apertura de una cuenta única a una persona en la que las operaciones se trasladaban a asientos de cargos y abonos que se compensaban en un saldo final cuando se cerraba la cuenta".

${ }^{48}$ E. CRuselles Gómez, Los comerciantes, p. 96 y ss. 
La primera referencia que fue esgrimida por los demandantes nos habla de la constitución de una compañía comercial, o por mejor decir, de la ratificación de una compañía como apunta en su libro Bernat Valldaura. La compañía estaría formada por Arnau Pujamar, de Tortosa, que ostentaría la razón social, Bernat Valldaura, Domingo Aznar y Francesc Rovira. Los dos primeros coparían la parte sustancial del capital, hasta casi el ochenta y cinco por ciento del total, mientras que Aznar apenas dispondría del doce por ciento y Rovira no llegaría al cuatro. Con estas cifras parece evidente que tanto Pujamar como Valldaura serían los auténticos inversionistas de la sociedad, quedando Aznar como aparente encargado de encontrar buenos negocios o gestionarlos y Rovira de la tramitación burocrática de los mismos.

En efecto, este último, Francesc Rovira, será el único que tenga un salario de cinco libras anuales, cabe pensar por los desvelos y trámites de la compañía, teniendo en cuenta además que parte de los socios residían en Valencia y la otra, que representaba a la razón social, en Tortosa. Además, Valldaura cobraría hasta veinte libras anuales por una bestia y un macip, que probablemente pondría en contacto a los socios de la compañía. Pujamar, que residía fuera de Valencia, también tendría a su disposición otro empleado, sin derecho a transporte, eso si, sin duda debido a que sería en Tortosa donde quedaba centralizada toda la gestión.

El propósito de la empresa era ganar dinero, que tendría que ser repartido en tres partes. Una para Pujamar, otra para Valldaura y la otra parte para Aznar. Quedaba así un porcentaje ínfimo, que sería repartido prorrateo entre los cuatro socios ${ }^{49}$. En síntesis, podemos llegar a establecer un cuadro de lo aportado a la compañía y lo obtenido de ella. Gracias a esta reflexión podremos justificar la afirmación que hemos hecho anteriormente respecto de las contribuciones financieras de los dos primeros socios y las aportaciones de negociante y gestor del tercero y en menor medida del cuarto.

PARTICIPACIÓN DE LOS SOCIOS

EN EL CAPITAL Y LOS BENEFICIOS DE LA COMPAÑÍA DE PUJAMAR EN 1346

En porcentajes.

\begin{tabular}{|l|c|c|c|}
\hline & Capital & Beneficios & Cobros de la Cía. \\
\hline Arnau Pujamar & $42^{\prime} 25 \%$ & $33^{\prime} 33 \%$ & $0^{\prime} 46 \%$ \\
\hline Bernat Valldaura & $42^{\prime} 25 \%$ & $33^{\prime} 33 \%$ & $0^{\prime} 92 \%$ \\
\hline Domingo Aznar & $1^{\prime} 65 \%$ & $33^{\prime} 33 \%$ & $0^{\prime} 00 \%$ \\
\hline Francesc Rovira & $3^{\prime} 85 \%$ & $0^{\prime} 01 \%$ & $0^{\prime} 23 \%$ \\
\hline
\end{tabular}

Como decíamos más arriba, se trataba de una actualización, una remodelación de una compañía que venía funcionando, como mínimo, desde 1340, según se informó a lo largo de la demanda ${ }^{50}$.

\footnotetext{
${ }^{49}$ AMV, Ibidem, mà 2a ${ }^{\text {a }}$ f. 38 rv.

50 "Primerament, diu lo dit En Pere d'Òdena, en lo dit nom, que lo dit En Bernat de Valldaura et N'Arnau Pugamar, mercader // de Tortosa. Et lo dit En Domingo Aznar e En Francesc Rovira feren companya et succetat sobre totes lur mercaderies, en l'any de Nostre Senyor M CCC XL. Et en la qual companya lo dit En Bernat mes nou-centes lliures, et lo dit N'Arnau altres nou-centes, et lo dit En Domingo doentes XL lliures e lo dit En Francesch Rovira LXXX lliures, segons que per carta feyta en Tortosa, per En [en blanco] notari, que per lo libre d'En Bernat, scrit de la sua mà pròpia, de la qual scriptura dessús, fa fe les dites coses pus largament aparen". AMV, Ibidem, mà 2a, ff. 22v-23r.
} 


\author{
PARTICIPACIÓN DE LOS SOCIOS \\ EN EL CAPITAL DE LA COMPAÑÍA DE PUJAMAR EN 1340
}

\author{
Arnau Pujamar \\ Bernat Valldaura \\ Domingo Aznar \\ Francesc Rovira
}

En porcentajes

$42 ' 45 \%$

$42,45 \%$

11 ' $33 \%$

$3,77 \%$

Sin embargo, no cabe duda de que esta estructura societaria no fuera la que se hallaba presente en la organización de la compañía, afectada por el asalto de la Sant Nicolau. Se menciona, en algún lugar también, la existencia de una segunda compañía mercantil, al margen de la de Pujamar, en la que éste no tendría participación $^{51}$. Tampoco queda clara cual sería la del resto de las partes. Al contrario que en momentos anteriores, las afirmaciones recogidas no van seguidas por documentos notariales claros, muy al contrario, quedan envueltos en cierto halo de indeterminación. En esta ocasión el registro contable de Valldaura no especifica nada o no quisieron los pleiteantes hacer uso de él.

Al parecer el propósito final de esta nueva sociedad, en la que solamente estaban presentes Bernat Valldaura y Domingo Aznar era realizar una travesía hacia Lisboa, sabemos por otras fuentes que incluso se contemplaba la posibilidad de llegar a los puertos gallegos ${ }^{52}$. La parte de estos dos mercaderes y financieros se circunscribiría a las mercancías transportadas, quedando a los otros socios, Pere Dezpuig, reconocido como señor y patrón de la nao, y Guillem Domingo, escribano, la otra parte de la compañía. Cabe especular con la idea de que Valldaura y Aznar se encargarían de las mercancías y Dezpuig y Domingo correrían con los gastos del viaje, incluyendo el aparejo de la coca. Como dijimos más arriba, no está demostrado que los géneros robados fueran propiedad de Aznar y Valldaura. Puede ser que solamente se hubiese pactado repartir el beneficio obtenido o la pérdida en caso de una venta a la baja, pero no se menciona nada de las repercusiones del latrocinio. Las mercancías robadas no pertenecían a Domingo y Dezpuig en este caso y caben dudas razonables de que fueran de Valldaura, pero parece inequívoco que pertenecieron, en buena parte, a Aznar.

PARTICIPACIÓN DE LOS SOCIOS
EN EL CAPITAL DE LA COMPAÑÍA DE COMERCIO CON PORT
COMPAÑÍA VALLDAURA-AZNAR
COMPAÑÍA DEZPUIG-DOMINGO

\footnotetext{
51“'Item, diu En Pere d'Òdena que lo dit En Bernat de Valldaura, pare dels dits hereus, poch temps ajats de la dita confecció de la dita companya, dels diners d'aquella per guanyat e multiplicament, ensemps ab lo dit En Domingo, d'una part, e En Pere Dezpuig, patró d'una cocha apel-lada Sent Nicholau et En Guillem Domingo, scrivà, d'altra, feren companya e societat en sobre diverses robes e mercaderies, les quals lo dit En Bernat e En Domingo carregaren en la dita cocha, ço és en aquesta forma: que los dits En Bernat e En Domingo meteren en la dita companya lo càrrech e lo dit En Pere hagués [sic] e En Guillem Domingo meteren en la dita companya la dita cocha e que ab aquella fessen viatge a les parts de Lisbona, e que del guany e pèrdua que Déus daria en la dita mercaderia haguessen lo dit En Bernat e En Domingo la meytat del guany que Déus daria en les dites mercaderies e los dits En Pere e En Guillem l'altra meytat, segons que per carta desús fa fe pus largament apar". AMV, Ibidem, mà $2^{\mathrm{a}}$, f. 23 r.

${ }^{52} \mathrm{AMV}$, Ibidem, mà $2^{\mathrm{a}}$, f. $28 \mathrm{v}$.
} 
El segundo de los documentos que aparecía trascrito íntegramente, entre los papeles del pleito de los herederos de Valldaura y su tutor Aznar, es otra página del supuesto libro del mercader, en la que se recogen los gastos habidos a consecuencia de las reclamaciones. El papel, pese a su lamentable estado, nos permite adivinar los balances de cuentas. En un principio quedará registrado todo aquello que la sociedad implicada en el latrocinio tuvo que invertir en hacer las reclamaciones, tanto en Valencia, como cerca del rey de Francia o en la misma Lisboa. En total ascendía a veintitrés libras con dos dineros, a los que habría que sumar las quinientas ochenta y cuatro libras robadas por los genoveso-provenzales, ascendiendo a un total de seiscientas siete libras con dos dineros, que transformados en florines, a doce sueldos y medio por florín suman una cantidad de novecientos setenta y un florín y medio ${ }^{53}$.

Nosotros, no obstante, en lo que verdaderamente estamos interesados es en la composición de los asientos que constituyen esta cuenta. No vamos a decir que sean de una claridad meridiana pero si que se construyó con la suficiente solvencia como para que se pudiera explicar por sí sola. Por este orden aparece la cantidad de pérdidas totales, los gastos necesarios en presentar las reclamaciones ante el monarca francés y las autoridades valencianas. En tercer lugar figura el dinero empleado en Lisboa para obtener la carta testimonial del latrocinio y por último el cambio de la moneda de cuenta, que era la libra, al florín y el beneficio extra que eso produjo, cuando las autoridades reales valencianas fallaron la cuantía de la marca para los siniestrados. Todo esto nos lleva a pensar que el libro de Valldaura contenía verdaderas tendencias hacia el seguimiento contable de partida simple. Es cierto que, junto a esta tendencia, hallamos muestras palpables de posible desorganización. Hemos visto como se pormenorizaba, razonablemente, la estructura de la sociedad mercantil de la que formaban parte Aznar y Valldaura, sabemos incluso que en su origen, en 1340, fue muy similar a como funcionaba en 1346, pero es muy vago cuanto dejó, repetimos, aparentemente escrito, Valldaura, en su registro de cuentas, sobre la empresa para pasar a Lisboa.

Probablemente, llegado este punto, hemos de hablar de la evolución contable, de la transición desde el memorándum hasta la partida simple. Esa evolución fue lenta, por eso Cruselles no llegó a apreciarla hasta cincuenta años más tarde, pero sin duda no se produjeron, ex nihilo, los cambios detectados en los comienzos del siglo $\mathrm{XV}$. Sobre eso, sobre cambios y evoluciones, y sobre nuestra completa carencia de fe en los fenómenos ex nihilo versará la última parte de este trabajo.

\section{LA MARCA CONTRA FRANCESES Y LA INCLUSIÓN DE LOS MERCADERES AFECTADOS EN LA RED DE REINTEGRACIÓN DE DINERO ROBADO}

Las autoridades comunales valencianas nunca fueron partidarias de intervenir contra navegantes inocentes a favor de otros comerciantes, incluso autóctonos, que hicieran uso de derecho de marca. La razón fundamental, tal vez, era que los jurados y el Consell temían la no llegada de barcos al Grau de la mar y el desabastecimiento de productos, especialmente de cereal ${ }^{54}$. Desde 1313 Jaime el Justo y Felipe VI, de Francia, intentaban encontrar puntos de encuentro que sirvieran para aliviar las tensiones políticas que se producían, como consecuencia de asaltos corsarios en tiempo de paz. Las

\footnotetext{
${ }^{53}$ AMV, Ibidem, mà 2a , ff. 38v-39r.

${ }^{54}$ El día 9 de junio de 1346, unos mercaderes franceses se quejaban de haber sufrido la captura de sus bienes como consecuencia de la aplicación del derecho de marca contra sus bienes. El Consell de la ciudad, solicita de la autoridad real la revocación de la marca que perjudica e interrumpe la libre llegada de mercancías a la capital AMV, Manuals de Consells, A-6, ff. 11r-12r.
} 
negociaciones no solo fueron difíciles sino que estuvieron entorpecidas por nuevas complicaciones que, periódicamente, acechaban las reuniones. Por ese motivo, la iniciativa acabó convirtiéndose en una simple intención, hasta que, durante el reinado de Pedro el Ceremonioso y Juan II de Francia, se consiguió el tan anhelado acuerdo definitivo, en $1351^{55}$. Semejante logro, sin género de duda, sería aplaudido por los rectores políticos de la capital valenciana, pese a que, en definitiva, el acuerdo entre el Ceremonioso y el monarca francés venía a dinamitar buena parte de las tan trabajosamente amasadas relaciones mercantiles entre aquellos territorios y el reino de Valencia. De cualquier modo, eso era mucho mejor que tener que verse sometidos a continuas disputas y a la fijación de nuevas marcas, que constantemente se sucedían, como pasaba un poco de tiempo antes ${ }^{56}$.

La solución encontrada, por la comisión técnica que verificaba los acuerdos entre la Corona de Aragón y la de Francia, no fue nada original, limitándose a algo tan poco creativo como alumbrar una nueva tasa, una especie de arancel, que cargase todas las mercancías con origen o destino en Francia o la Corona de Aragón. Este gravamen sería de tres dineros por libra o lo que es lo mismo, del uno con veinticinco por $\operatorname{cien}^{57}$. La recaudación del dinero se haría como era corriente en esta época. Se ajustaría un sistema de arrendamiento de la tasa, en pública subasta, que sería explotada por el que hubiese ganado un concurso público, vigente por un año de plazo. Por último, se establecía que aquellas personas, afectadas por robos a manos de la otra parte, tendrían ocasión de resarcirse de las pérdidas habidas, quedando designados dos representantes por cada señoría, que se encargarían del gobierno del gravamen ${ }^{58}$. Las seiscientas siete libras totales que pensaba Valldaura que le debían los franceses o las seiscientas siete libras con tres sueldos y cuatro dineros que le reconoció el Baile General, según testimonio reconocido en el pleito entre Aznar y los herederos de los Valldaura, serían aumentados todos los años hasta dos sueldos por libra jun veinte por cien! cantidad exorbitante en comparación con la fijación de la tasa del uno con veinticinco por ciento que hemos visto antes ${ }^{59}$. Parece evidente que los intereses de Aznar y sus socios constituían un negocio casi usurario, en los años inmediatamente posteriores a la comisión de la tropelía, que, como vamos a ver, quedó atemperada a partir de 1351 con la fijación del gravamen contra mercancías francesas.

En efecto, hemos comprobado cuales eran los elementos básicos que constituían los fundamentos de la imposición, que gravaba el comercio bilateral, entre súbditos de la Corona de Aragón y de Francia. Sabíamos, por la exposición esclarecedora que hizo Josefina Mutgé, que no se conocía el montante total de las tropelías, ni qué parte correspondería a Francia y cual a la Corona de Aragón. No obstante, se planteaba la hipótesis de que dos tercios de las pérdidas fueran ocasionadas por súbditos del rey de Aragón y el otro tercio por súbditos del rey de Francia. De esta manera la repartición, de lo puesto en común de la tasa fijada, cubriría el doble de tropelías catalano-aragonesas

\footnotetext{
${ }^{55}$ Josefina MUTGÉ I VIVES, La inseguretat en el Mediterrani occidental. Acord entre el rei catalanoaragonès Pere el Cerimoniós i el francès Joan II de Valois per a la solució de les marques existents entre ambdós regnes en La Corona catalanoaragonesa i el seu entorn mediterrani a la Baixa Edat Mitjana, Barcelona, 2005, pp. 185-203, en especial pp. 187-188

${ }_{56}$ AMV, Reebedor de Pere Monçó, aa-1 (1344-1345). Doc. fechado a 16 kalendas de diciembre de 1344. Se trata de una copia notarial en la que se especifica la fijación de marcas contra las galeras de Colliure, por tropelías cometidas contra mercantes valencianos.

${ }^{57}$ J. MUTGÉ I VIVES, La inseguretat en el Mediterrani occidental, p. 190.

${ }^{58}$ J. MuTGÉ I VIVES, La inseguretat en el Mediterrani occidental, pp. 190 y ss.

${ }^{59} \mathrm{AMV}$, Ibidem, mà $2^{\mathrm{a}}$, f. $37 \mathrm{r}$.
} 
que francesas ${ }^{60}$. En nuestro documento aparece, no ya una hipótesis de trabajo sino una verificación cierta de los valores globales, que fueron tomados como reales. Se trataría de treinta y cinco mil seiscientas cuarenta libras o treinta y cinco mil cuarenta libras ${ }^{61}$. Si tenemos que hacer caso a la reflexión de los legados de las dos señorías, que pactaron la fijación del gravamen comercial de las transacciones bilaterales, tendríamos que considerar esa cantidad, que le correspondía al territorio de la Corona de Aragón, como un tercio del total, por lo que habríamos de multiplicar esa cantidad por tres, hasta las ciento seis mil novecientas veinte libras, en que cabría evaluar el coste sordo de una guerra no reconocida por las partes, casi un millón trescientos mil florines, contándolos a doce sueldos la pieza ${ }^{62}$.

De las treinta y cinco mil seiscientas cuarenta libras ${ }^{63}$, correspondían a los siniestrados en el cabo San Vicente seiscientos setenta y cuatro libras cuatro sueldos y ocho dineros. Esta cifra era el resultado de las pérdidas habidas en alta mar, más los gastos desembolsados en solicitar la devolución de lo robado, junto a los intereses que se estipularon para penalizar la tardanza de resarcir a las víctimas. Así pues, se calculó lo robado en quinientas ochenta y dos libras con dieciocho sueldos, que se transformaron en florines, al cambio de doce sueldos por florín ${ }^{64}$. A esta cifra habría que añadir noventa y una libras seis sueldos y ocho dineros, por demora en el cobro de lo robado ${ }^{65}$. Así pues, en total, el monto definitivo ascendía a seiscientos setenta y cuatro libras cuatro sueldos y ocho dineros ${ }^{66}$.

Hemos visto aquello que se puede considerar los números esenciales de la marca. En síntesis, da la sensación de que los afectados por la tropelía buscaron engrandecer las pérdidas, es cierto que eso resultaba difícil, ante la probable valoración

${ }^{60}$ J. MuTGÉ I VIVES, La inseguretat en el Mediterrani occidental, pp. 191-192. “A la normativa, s'hi posava un senzill exemple: si el total degut als súbdits francesos atenyia la suma de 100.000 lliures, i el que es devia als súbdits de la Corona d'Aragó era de 50.000, els de França rebrien dues parts del total recaptat amb els impostos i, els súbdits catalanaoaragonesos, una tercera part. La suma recaptada pels impostos es repartiria proporcionalment".

${ }^{61}$ AMV, Ibidem, mà 2a , f. 22 r. Ambas cantidades aparecen en el mismo folio, probablemente tratándose en el segundo caso de un error del copista.

${ }^{62}$ J. MutGÉ I VIVES, La inseguretat en el Mediterrani occidental, pp. 199-201. Proporciona una nómina completa de afectados de las dos soberanías y pérdidas habidas, aunque en algunos casos informa de que esas cifras no deben ser tomadas en consideración por causas diversas.

${ }^{63}$ Esta cifra corresponde a la tasación de "XXXV Mília DC XL lliures qui.ns són ajustades sobre la imposició dels tres diners per lliura qui.s paga en lo regne d'Aragó e de França, per lo feyt de les marques". AMV, Ibidem, mà 2a , f. 22r. Aparece en el mismo folio una cantidad muy parecida pero distinta de la anterior: 35.040 libras, que sería la cantidad por la que era preciso satisfacer el derecho de sello al monarca. Probablemente hasta 600 libras estarían exentas de gastos por diversos motivos.

${ }^{64}$ Se menciona que 582 libras con $18 \mathrm{~s}$, cantidad de dinero que representaría el valor de lo perdido por la nave de Bartolomeu Gili en junio de 1347, multiplicado por 12 sueldos, para transformar en moneda efectiva lo que era una simple moneda de cuenta daba como total 971 florines y medio. AMV, Ibidem, mà 2a , f. 22r. No obstante, en otras ocasiones la cantidad anotada será de 584 libras. AMV, Ibidem, mà $2^{\text {a }}$, f. 37v. Domingo Aznar justificará que era esa la cifra final debida, de igual manera que exigía el pago de "II sous per lliura de interès per cascun any prop passat tro la sobredita quantitat sia pagada, com lo dit interès en semblant cas sia acostumat pagar”. También el hipotético libro de Valldaura contemplaba exigir 584 libras o al menos esa era la cifra a partir de la cual exigían los afectados un $3 \%$ para los mensajeros encargados de defender su causa ante el rey de Francia, es decir 17 libras y $10 \mathrm{~s}$. AMV, Ibidem, mà $2^{\mathrm{a}}$, f. $38 \mathrm{v}$. Esta cantidad era el fruto de la evaluación de pérdidas realizada en Lisboa, según la cual los estragos llegaron a los 730 escudos, que a $16 \mathrm{~s}$ por unidad dan las 580 libras. AMV, Ibidem, mà $2^{\mathrm{a}}$, f. $35 \mathrm{v}$.

${ }^{65}$ Esta cantidad es el fruto de aplicar a la cifra que todavía no se habría satisfecho: 576 libras $16 \mathrm{~s}$ y $10 \mathrm{~d}$ un $15^{\prime} 83 \%$, por libra, es decir, 3 s 2 d. AMV, Ibidem, f. 22 r.

${ }^{66}$ AMV, Ibidem, f. 22r. 
objetiva de las autoridades lisboetas, pero resultó más fácil cuando nos referimos a los oficiales reales valencianos. Efectivamente, éstos no debieron poner muchas objeciones a la justificación de gastos de los robados, que en ocasiones se limitaron a jurar que las cifras aportadas se correspondían con la realidad, sin que fuera posible mayor certificación. No obstante, la disputa entre Aznar y los herederos de Valldaura nos permite adentrarnos en cierta especificación que puede ser valiosa a la hora de cerciorarnos de la evolución de la marca. Existe una diferencia entre las cuentas de gastos, según las interpreten Aznar o el presunto libro de mercader de Valldaura. Es cierto que encontramos valores comunes pero también hay apreciaciones distintas que conviene tener en cuenta. En cualquier caso, es cierto que todos estos gastos nos permiten distinguir el proceso que se siguió, pormenorizadamente, hasta la consecución de la marca y los ingresos que generó.

Entre las coincidencias habidas, según Aznar y Valldaura, figuran los gastos en la procuració, que En Pere Dezpuig hizo a Aznar, como encargado de la defensa de su parte de la compañía, para reclamar las pérdidas ${ }^{67}$. Recordemos que la sociedad estaría constituida, básicamente, por Pere Dezpuig y Guillem Domingo, por Bernat Valldaura y Domingo Aznar serían la otra parte de los partícipes. También aparece la traducción del portugués, realizada por En Copons, del documento elaborado y presentado en Lisboa $^{68}$. Coinciden, igualmente, en el pago del asesor de la Bailía, Domingo Eymerich, encargado de la evaluación del dinero de la marca ${ }^{69}$. En ambas cuentas aparece también el pago al saig, que se encargó de llevar el expediente de la Bailía a casa de Eymerich y viceversa ${ }^{70}$. Por último, son paralelas las cantidades satisfechas a los mensajeros destacados en Francia, que recibieron una importante cantidad de dinero ${ }^{71}$. Hay además un caso que, aunque no es idéntico en ambas cuentas, si puede refundirse hasta comprender que se trata del mismo asiento. Se trata del pago de la formación del expediente que fue instruido en la Bailía, tarea realizada por Domingo Gascó ${ }^{72}$.

Hay un par de casos en los que se aprecia una discrepancia en los números aportados por las partes. Nos referimos al coste de la carta de reconocimiento de asalto, que las autoridades portuguesas redactaron ${ }^{73}$. El otro caso si es más peliagudo porque no tenemos posibilidad de hallar una explicación convincente. Se trata del asiento conside-

${ }^{67}$ Aparece en las cuentas aportadas por Aznar y Valldaura, hasta un total de $6 \mathrm{~d}$. AMV, Ibidem, mà $2^{\mathrm{a}}$, f. 37v para el caso de Aznar y f. 38v para las cuentas de Valldaura.

${ }^{68}$ Fueron necesarios $12 \mathrm{~s}$, para las cuentas de Anzar AMV, Ibidem, mà 2a , f. 37v y f. 39r para las de Valldaura, donde se nos proporciona un interesante complemento informativo: "Item, doní a.N Copons, per trelladar la carta que.s feu a Lixbona de la requisició".

${ }^{69}$ AMV, Ibidem, mà $2^{a}$ f. 37v, para el caso de Aznar y f. 39r para el de Valldaura, que explica: "Item doní, a.N Domingo Eymerich, assesor del Batle, per acordar la suma".

${ }^{70}$ AMV, Ibidem, mà $2^{a}$, f. $37 \mathrm{v}$ y f. 39r.

${ }^{71}$ Los legados encargados de llevar los asuntos valencianos ante las autoridades francesas fueron Guillem de Figues, de Barcelona y Guillem de Termens, de Mallorca. AMV, Ibidem, mà 2a f. 37v y f. $38 \mathrm{v}$.

${ }^{72}$ Este oficial real aparece citado en ambos documentos, pero en el de Aznar figuran dos asientos. El primero de $2 \mathrm{~s}$ "per ordenar la requisició o demanda posada de la dita marca en la Cort de la dita Batlia". El segundo para ordenar estos trabajos, se desembolsó 6 d. Por lo tanto la cuantía total sería de 2 s 6 d, AMV, Ibidem, mà $2^{\mathrm{a}}$ f. 37v. Valldaura anotará en su libro, por otro lado: "Item, a.N Domingo Gascó, per la requisició que ordena”, pagará 2 s 6 d. AMV, Ibidem, mà 2ª f. 39r.

${ }^{73}$ Aznar hablará de 2 libras y 4 dineros frente a las 2 libras y 4 sueldos que anotó Valldaura. AMV, Ibidem, mà $2^{\mathrm{a}}$ f. $37 \mathrm{v}$ y f. $39 \mathrm{r}$ respectivamente. Es bien cierto que la suma total de las cuentas de Aznar no casaría si se tuviera en consideración este dato. Por el contrario, los 463 s 4 d solamente encajan si se consideran los aparentes $4 \mathrm{~d}$ como sueldos, y por lo tanto podemos presumir de que se trata de un error del escribano más que de una discrepancia entre las partes. 
rado en las cuentas de Aznar como dinero necesario para que el escribano de la Bailía copiase el proceso y lo legalizase, con sello pendiente. Los asientos de Valldaura, aquí están más claros. Por la copia del manuscrito se pagará una cantidad, mientras que por su factura en papel sellado se satisfará otra distinta ${ }^{74}$. Es por eso que la suma total de los gastos aducidos, por Valldaura, coincide perfectamente y es sensiblemente próxima a la reclamación definitiva, mientras que la de Aznar rebasa esa cantidad solicitada.

Podemos encontrar, a lo largo del proceso, todavía otras dos cuentas que conviene esclarecer. La primera, es sin duda, la menos interesante. Se trata de la continuación de las anotaciones en el supuesto libro de mercader de Valldaura. Éste, según parece querer asegurar los defensores de la causa de sus herederos, reconocía haber tenido unos gastos extra, en Lisboa así como no haber pagado otros gastos extra en Francia, para reclamar lo robado ${ }^{75}$.

\title{
GASTOS ALEGADOS POR LOS HEREDEROS DE BERNAT VALLDAURA COMO DERECHOS AL COBRO DE LA MARCA
}

\author{
Desembolso en Valencia \\ Desembolso en Lisboa \\ TOTAL \\ Pérdida en la tropelía \\ TOTAL RECLAMADO
}

\begin{abstract}
20 libras 15 sueldos 4 dineros
2 libras 4 sueldos

22 libras 19 sueldos 4 dineros

584 libras 19 sueldos 4 dineros

607 libras aproximadamente
\end{abstract}

\section{GASTOS ALEGADOS POR DOMINGO AZNAR \\ COMO DERECHOS AL COBRO DE LA MARCA}

Desembolso total
Pérdida en la tropelía
TOTAL RECLAMADO
23 libras 13 sueldos 4 dineros

584 libras

607 libras 13 sueldos 4 dineros

Desconocemos la veracidad de estos datos aunque podamos pensar que representan una cierta exageración, al no aparecer en ningún otro papel aducido en el proceso. Además su valoración no se hará como alegato para incrementar lo desembolsado por Valldaura sino para hacer una prueba pericial de comparativa caligráfica con la letra de Aznar, quien tuvo, por algún tiempo, el libro de Bernat. En efecto, Domingo Aznar se encargará de anotar, en un asiento inmediatamente posterior a los anteriores, el balance de cuentas ${ }^{76}$. Sobre este resultado total, Aznar hará recaer el pago del flete que quedaba pendiente, a favor de la compañía, por una carga de cajas de sardinas dejando la cuenta con el difunto Valldaura a cero ${ }^{77}$.

\footnotetext{
${ }^{74}$ Por la primera anotación, de Aznar, se escribieron $34 \mathrm{~s}$, AMV, Ibidem, mà $2^{\mathrm{a}}$ f. $37 \mathrm{v}$, mientras que por la segunda y tercera, las de Valldaura se inscribieron $12 \mathrm{~s}$ y $18 \mathrm{~s}$ respectivamente, en total $30 \mathrm{~s}$, razón por la que apreciamos una diferencia de $4 \mathrm{~s}$, entre uno y otro escrito.

${ }^{75}$ En Lisboa fue necesario desembolsar hasta 20 libras $15 \mathrm{~s} 10 \mathrm{~d}$ para conseguir que las autoridades redactaran el documento, que por cierto costó la décima parte aproximadamente. Cabría entender que fue necesario convencer a los oficiales lisboetas con contantes razones o que Valldaura engrandeció un gasto que no había existido. El segundo de los asientos es el reconocimiento de un débito por parte de Bernat a la compañía de 20 libras, por las gestiones que se realizaron ante el rey francés. AMV, Ibidem, mà $2^{\mathrm{a}}$ f. 39r.

${ }^{76}$ Los gastos en Lisboa, menos los habidos en Francia, daban un resultado a favor de Bernat Valldaura de $15 \mathrm{~s} \mathrm{y} 10 \mathrm{~d}$, anotado de puño y letra por Aznar. AMV, Ibidem, mà $2^{\mathrm{a}}$ f. 39v.

${ }^{77} \mathrm{AMV}$, Ibidem, mà $2^{\mathrm{a}} \mathrm{ff} .39 \mathrm{v}-40 \mathrm{r}$.
} 
Queda por resolver la complicada cuestión de la marca. En el proceso, que hemos analizado, se dilucidaba, entre otras muchas cosas, que parte del dinero perdido, en el asalto corsario, pertenecía a Domingo Aznar y que parte a Bernat Valldaura. En esta compleja disputa intervendrá Pere d'Odena, que se declarará acreedor de Aznar. Al parecer Odena se había encargado de las tareas de defender los intereses de los afectados valencianos por la tropelía en la gestión de establecer la marca, durante el período que va desde el inicio de esta comisión, probablemente 1348, hasta finales de 1351, cabe pensar hasta los acuerdos entre la señoría del rey de Francia y el monarca catalanoaragonés. No existe ninguna constancia que nos informe del momento exacto en el que se comenzaría a cobrar dinero por la marca en Valencia, pero por simple deducción parece lógico que fuera a partir del comienzo de 1349 o a finales de 1348 . Pere d'Òdena reclamaba su salario y hacía responsable a Domingo Aznar de ser el único responsable de su impago. Además, adoptando una postura favorable a la parte contraria de Aznar, había testificado contra Domingo Aznar, acusándole de haberse apropiado indebidamente del dinero de la marca, que corresponderían a los herederos de Bernat Valldaura.

Las acusaciones de Òdena, al margen de su fundamento, quedaban ensombrecidas por la sospecha de una duda razonable, veámoslo. No parece muy coherente acusar a Aznar de no tener derecho a cobrar la mayor parte de la marca y luego exigir el pago de una deuda generada por la gestión del trámite de su puesta en marcha ${ }^{78}$. En definitiva, no resultó sencillo a los jueces atribuir mucha credibilidad a este personaje, que al final, por otro lado, estuvo dispuesto a arreglar su contencioso personal con Domingo a través de un acuerdo amistoso extrajudicial ${ }^{79}$.

Por fin, al margen de otros gastos y deudas, los pagos anuales del dinero de la marca, que funcionaría como un auténtico impuesto, se prolongaran por una gran cantidad de tiempo. En 1355 , se acometía la séptima campaña de cobro de la tasa ${ }^{80}$. Siempre se entregaba una cantidad fija, que coincidió con la cantidad del salario de Òdena. De este modo, los plazos anuales de dinero, en cantidad muy escasa, probablemente no llegarían a compensar los intereses que se iban agregando al monto originario. En resumidas cuentas, la tasa que se había fijado, jamás podría abolirse porque los mecanismos que hacían que funcionara retroalimentaban la deuda, haciendo imposible su satisfacción e incrementando el pasivo hasta el infinito. Es así como muchas tasas acababan siendo irreversibles. Se convertían en auténticas inversiones, si se nos permite la comparación, al estilo de los censales, dinero que jamás se sabía cuando sería reembolsado pero que daba una cantidad fija anual garantizada.

Marcas, libros de cuentas y procedimientos recaudatorios privados tuvieron algún tipo de peso en la sociedad valenciana de la primera parte del trescientos. Se trata de tres elementos, aparentemente diversos, que tuvieron una estrecha relación y contribuyeron a configurar la actividad económica valenciana de la época.

Fecha de recepción del artículo: Marzo de 2009

Fecha de aceptación y versión final: Diciembre 2009

\footnotetext{
78 “Ítem, me deu per lo salari que fo a mi tatxat per los perdents de València de tot lo temps que havie seguides les marques tro a XXI de deembre M CCC LI, XII diners per lliura, segons apar per carta feta per mà d'En Francesch Martorell, scrivà de València. Muntà XXXIII lliures XIIII sous". AMV, Ibidem, mà $2^{\mathrm{a}}$, f. $22 \mathrm{r}$.

${ }^{79}$ AMV, Ibidem, mà $2^{\mathrm{a}}$, ff. $21 \mathrm{v}-22 \mathrm{r}$.

${ }^{80}$ AMV, Ibidem, mà $2^{\mathrm{a}}$, ff. 39v-40r.
} 